\title{
EXPERIMENTAL STUDIES OF HYBRIDIZATION AMONG DUCKS AND PHEASANTS

\author{
JOHN C. PHILLIPS
}

NINE PLATES

\section{INTRODUCTION}

The following experiments were started in 1909 and 1910 with the idea of studying plumage characters in wild species of birds. All the following crosses may be regarded as between wild species, except the Black East India experiment, the 'freak' mallard experiment, and the albino pheasant experiment.

In the ducks the mallard has always been used as one of the parents. These mallards were all from the same strain as that used in the size crosses (24). They are a pure strain of English mallards, such as are used in English game parks. During the years in which this strain has been bred here, about 500 of these birds have been reared. No departure from type has been noted except two freak ducklings in 1909 (see 'freak' mallard experiment), and one in 1913.

Reciprocal duck crosses were attempted with the mallard as male parent and the black-duck, pintail, and Australian as the female parent, but in the small mating pens it was found impossible to induce the females of these latter species to lay.

It is scarcely necessary to describe the mallard duck. The mallard characters dealt with in the following pages are, green head, white neck ring, chestnut breast, curly sex feathers in the tail, vermiculated abdomen and flanks, and white anterior and posterior bars to the purple speculum of the wing. Each experiment is described separately in the following pages. 


\section{PINTAIL MALLARD EXPERIMENT}

\section{A cross between two sexually dimorphic species}

In 1910 two pure wild male pintail ducks (Dafila acuta), Nos. 108 and 109, were placed in a mating pen with two female mallards, Nos. 141 and 142, from the original mallard stock described above (cross $R$ 1910). From this mating a large number of eggs were gathered, but only seven individuals hatched out, of which six were reared to maturity, male 105, and females $102,103,104,91$, and 72 . The appearance of hybrids produced by this cross has often been described, but will be given in detail later on. Both males and females are distinctly intermediate in color, shape, and general carriage, but the females of the parent species do not differ in any striking peculiarities, so that the female hybrids may be disregarded in this account.

During the years 1911, 1912 and 1913, a number of $F_{2}$ birds were reared from the six $F_{1}$ ducks of 1910 . Only one mating could be made each year on account of having only one $F_{i}$ male, so that the numbers reared are not as large as could be wished. The $F_{1}$ ducks do not lay freely, at least not in the space which could be accorded to them. In all there are only sixteen $F_{2}$ males.

In 1913 a large number of pure wild male pintail ducks were placed in a large pen together with a number of female mallards of exactly the same stock used in the first cross (1910). From this mating about a hundred birds were reared to maturity and forty-six $F_{1}$ males were carefully studied (cross $N$ 1913).

The skins of eleven $F_{2}$ hybrids and seven $F_{1}$ hybrids were preseryed and notes made on all the other specimens. It may be remarked in passing that there is a very striking resemblance between $F_{1}$ and $F_{2}$ birds, and, except for one or two characters, there does not seem to be any more tendency to variation among $F_{2}$ than among $\mathrm{F}_{1}$ hybrids. Plates 1 and 2 show males of the parent races, and the extreme variations of both generations. As there was a greater choice of numbers among the $F_{1}$ birds (forty-six as against sixteen), a tendency to greater variation among the $F_{2}$ 's than is here shown cannot be entirely ruled out, but the $F_{1}$ 
material may be considered as ample. In general it must be acknowledged that the first generation hybrids seem to have rather less of the mallard chestnut breast area than the second generation hybrids, but the difference is slight.

The pintail duck represents a genus of true ducks distinguished by their characteristic shape and elongated tails. The head is brown and the breast white, the white pointing far up the sides of the neck. The bill is lead blue, black on the nail and very different from the color of the mallard's bill. The mantle and flanks are finely vermiculated with gray and black. There is a black area on the scapular feathers, and the middle tail feathers are very long and thin. The speculum is green, framed in front by a brown bar and behind by a white one.

The typical $F_{1}$ hybrid may now be described and the variations from this type afterwards indicated (pl. 1, fig. 8; pl. 2, fig. 4).

$F_{1}$ male No. 966 (cross $N$ 1913) and type of $F_{1}$ generation. The bill is practically pure pintail in color, being a dull lead blue, black on the nail. In size and shape, however, the bill is probably exactly intermediate, as pointed out by Bigelow (1). The color of the head is a very dark purplish brown with a metallic gloss of green, which is much brighter on the post-ocular and hind-neck region. The crown of the head is more brownish and directly under the eyes is a small semilunar spot of white. Therefore the head color shows both the brilliant green of the mallard and the plain brown of the pintail.

The upper breast has the chestnut area of the mallard, but reduced both in extent and in depth of color (pl. 9, fig. 8), and not sharply marked off posteriorly, where it fades out into the pure white of the abdomen. This condition is exactly half way between the white upper breast of the pintail and the chestnut breast of the mallard (pl. 9, fig. 3). The chestnut area of the hybrid is sharply separated from the dark colored head by a white collar, which is wider than that of the mallard and tends to point up on the sides of the neck as in the pintail. The silver gray undulated appearance of the flanks and the plain gray color of the lower abdomen are absolutely intermediate. The under tail coverts are black as in both parent species. The 
mantle is gray with very fine black vermiculations, halfway between the coarser vermiculations of the pintail and the plain dark umber brown of the mallard. The rump is very dark, almost black, as in the mallard, but preserves a few of the lighter gray feathers of the pintail. The middle tail feathers have the elongation of the pintail and the upcurling of the mallard, but both characters in a modified form.

The speculum of the wing is very interesting, being a brilliant clear metallic green, nearest to the Veridian green of Ridgeway ('12). This is very unlike the purple blue of the mallard or the bronzy green to coppery color of the pintail, but more than likely it is directly due to an intermediate condition. The rest of the speculum preserves in a slightly modified form the anterior brown wing bar of the pintail, while its white posterior wing bar is not so wide as in the pintail, but wider than in the mallard. The legs and feet are dull orange yellow, not the brilliant orange of the mallard or the grayish black of the pintail.

I do not agree with Bigelow in finding any pure parental characters in the hybrid, with the possible exception of the color of the bill, and this is as often as not modified by a spot of dull yellow at the base of the culmen.

The rufous markings of the upper tail coverts, described in Bigelow's wild specimen, are not always present, and are scarcely important enough when present to warrant calling them a new character. The description of this hybrid could be made more complete, but the most important points have been enumerated.

The $F_{1}$ generation males show a measurable amount of variation, this variation being greatest in the chestnut breast area (pl. 1, figs. 7, 8, 9; pl. 2, figs. 3, 4, 5), in the form of the neckring, and in the color of the rump. The first two of these characters are ones that tend to vary most in the pure wild mallard and in domestic varieties. Also there is a slight range in the vermiculated appearance of the mantle. The colors of the head, the flanks, and the lower abdomen are very uniform. When the mallard chestnut breast area is much reduced, as in $F_{1}$ male 849 (pl. 1, fig. 9), there is always a widening of the white collar and a tendency for it to point forward along the sides of the neck, 
as in the pintail. There is always correlation between these characters, but this cannot be said of the mantle pattern and the rump color. The bill color runs from lead blue to yellowish blue, and the legs and feet from dull orange yellow to dullorange. The plate shows the total range of variation in the breast and neck areas, as seen in the two most divergent of the males. In or 849 (pl. 1, fig. 9), the chestnut area is very light colored, the feathers tipped with white, and the region fading into the pure white of the pintail breast. The white collar is $1.5 \mathrm{~cm}$. wide, ventrally, and over $3 \mathrm{~cm}$. wide dorsally. In the other extreme, $F_{1}$ or $^{753}$ or or $^{767}$, the chestnut area is nearly as great in extent as in the mallard, though less intense in color, while the collar is reduced to about the same size as that of the mallard parent (pl. 1, fig. 7). Between these types the other forty-five specimens show every possible shade and degree.

$F_{2}$ generation: On the whole this appears to lean towards the pintail parent rather more than the $F_{1}$ lot. The extreme bird is $F_{1}$ or 525 (pl. 1, fig. 11 ; pl. 2, fig. 7). In this specimen the chestnut area is reduced to a slight stain on the sides of the upper breast, while the lower parts, except the abdomen, are practically pure white. The white nape stripes of the pintail are very highly developed, as is the black nuchal area between them, while the whole head is much browner in color than that of any other specimen in either generation (this does not show in the plate). The mantle is very clearly vermiculated, and the rump light in color. The bill was lead blue in life, but with an orange spot at the base, while the legs and feet were pale dirty straw color. This specimen is certainly a distinct, though slight departure from the most extreme variation in the first hybrid generation. This specimen was almost duplicated by or 1217 (1913).

The extreme $F_{2}$ variation in the mallard direction is $0^{7} 530$, 1912 (pl. 1, fig. 10), in which the white collar is much reduced, and the head rather a brilliant green. It can be said with certainty that this bird shows a slightly greener (more mallard) head than any other specimen in either generation. Its bill was bluish lead color, and the legs and feet a dull orange. This bird was closely approached by or 1218 (1913). 
It has been noticed that the extreme $F_{2}$ variates are slightly farther removed from each other than are the variates of the first generation, although the smaller numbers of the $\mathrm{F}_{2}$ 's are against this result. The differences are very slight and not clear cut. Between the two $F_{2}$ extremes there fall the fourteen other specimens, the enumeration of which would take too much space. The bills of this series run from the pure lead-color type seen in many specimens, to a dull greenish yellow in or 675 (1912), showing on the whole a tendency to a little more range of color than the previous generation. The same thing is seen in the feet and legs, which run from a dirty straw color to a dull orange.

The sex feathers in this $F_{2}$ generation are much longer and better developed than in the $F_{1}$ 's, but this, $I$ believe, is entirely due to the fact that the $\mathrm{F}_{2}$ 's were allowed to grow older before being killed. There is a marked tendency for sex feathers to develop late in all mallard hybrids. It is certain that these $\mathbf{F}_{2}$ individuals were far less vigorous than the $F_{1}$ 's and their plumage developed later. In the best developed $F_{2}$ specimen the 'pin' of the tail is as long as in the pintail parent, but it is curved up to about half a circle, not tightly curled as in the mallard.

$F_{1}$ specimens of the 1913 hatch are now alive (February, 1914), and show tail feathers much longer than individuals killed for specimens in November.

\section{Back-cross, wild pintail ơ $\times$ pintail-mallard $\mathbf{F}_{1}$ \%}

This cross was made in 1913, a wild pintail male being mated with two of the original $F_{1}$ females (cross $F, 1913$ ). As a result three males and six females were reared to maturity (pl. 1, figs. 5 and 6). Two of the males and two females are still alive. On casual inspection the plumage of the males appears pure pintail, although the shape of the bird is distinctly mallard-like, the neck being short and the body chunky. This shape applies to both sexes. More careful inspection shows the head to be darker than the pintail, especially in throat and chin, with a slight iridescence lacking in the pintail. The black scapular patch of the pintail is almost entirely lacking, while the tail feathers 
are not plain, but irregularly barred. This last character is hard to account for, as it does not occur in either parent or in the first generation hybrids. Besides this, the upper tail coverts have considerably more black externally, extending even into the inner web in some cases. On the upper chest is a very faint blush of pink, barely noticeable, but without question the remains of the mallard chest area (pl. 9, fig. 11). The females are not easily distinguished from pintails, but they are browner.

Measurements bear out the observation that the $\frac{3}{4}$ pintails are chunkier than either pure pintails or $F_{1}$ hybrids. The following measurement, found to be a very uniform one, is the distance from the anterior point of the breast bone to the tip of the bill (Jour. Exp. Zool., vol. 16, p. 131) neck length:

$\begin{array}{lllll}\text { Pintail } & \sigma^{7} & 32.7 & \wp & 29.0 \\ \text { Mallard } & \sigma^{7} & 30.5 & \wp & 26.8 \\ \text { F }_{1} & \sigma^{7} & 32.0 & \wp & 27.4 \\ \frac{3}{3} \text { pintail } & \sigma^{7} & 30.2 & \wp & 26.0\end{array}$

Summary. There is thought to be a slight though definite tendency to more variation in $F_{2}$ hybrids than in $F_{1}$ hybrids in this cross. The first hybrids are shown to be as exact an intermediate in every detail as could possibly be imagined. They are shown to vary to a measurable extent, mostly in those characters that tend to vary in the mallard parent, the chestnut breast and white neck ring.

The $F_{2}$ hybrid material is not sufficient to establish beyond question the occurrence or non-occurrence of distinct Mendelizing characters, but indicates that Mendelizing units of a simple sort do not occur. It is expected that the number of $\mathrm{F}_{2}$ hybrids will be largely added to. Small as it is, it demonstrates the point stated above. It is doubtful whether any reasonable number of specimens of this generation will give any new types, but this can only be proved by further work.

The tendency to a more pintail appearance of the $F_{2}$ 's cannot be accounted for, as the original $F_{1} \sigma^{\top}$, still alive, is a good $F_{1}$ type. ${ }^{1}$

${ }^{1}$ Cross $J$ 1914, ơ (o⿱ pintail $\times \& \mathrm{~F}_{1}$ pintail $\times$ mallard $) \times \%$ mallard gave $16 \sigma^{7} \sigma^{7}$ which form a very uniform series, but show slightly more pronounced chestnut breasts than $F_{1} \sigma^{x} \sigma^{7}$. They are $\frac{3}{8}$ pintail and $\frac{5}{8}$ mallard. 
In the back cross with the pintail parent the female $\mathrm{F}_{2}$ hybrids have transmitted from their mallard mothers distinct mallard characters, involving both shape (cervical vertebrae length), color, and color pattern.

\section{Black duck (Anas tristis) and mallard crosses}

This cross involves the union of two species, only one of which has sex dimorphism; i.e., the mallard. It is analagous to the Australian-mallard crosses to be described next.

The black duck (pl. 3, fig. 3) is brownish black all over, the feathers margined with fulvous or gray. Both sexes are alike. The speculum of the wing is the same color as that of the mallard but it lacks the white bars, although a posterior one is sometimes developed to a slight extent. The top of the head is nearly black, and there is a dark post-ocular streak. The rest of the head and neck, down to that region which in the mallard is marked by a white collar, is grayish-fulvous streaked with dusky. This is perhaps the plainest colored species of the true ducks.

The cross was started in 1909, when two wild male black ducks were mated with two female call ducks. These call ducks came from a strain which had been bred by me for several generations, and showed no departure from the general mallard type, although somewhat more variation exists than among the English mallard stock used in all the other duck crosses. For purposes of convenience the call ducks may be regarded as pure mallard. They are in point of fact a rather coarsened mallard, with a more upright carriage, a higher voice, and a tendency to throw darker individuals occasionally.

The result of the 1909 cross was an $F_{1}$ generation composed of three males, Nos. 19, 22, 23; and four females, Nos. 24, 25, 26, and 27. These $F_{1}$ birds (pl. 3, fig. 4) were kept for several years, so that all delayed appearance of mallard characters may be ruled out. They may be described as dark intermediate types, showing plainly all the mallard characters, but obscured by the plain, dark brownish color of the black duck parent. The only mallard character which is strongly developed is the curly sex 
feathers in the tail, and these are not quite so long as in the mallard. To describe this hybrid more in detail: the postocular and hind-neck region is brilliant mallard green, the occiput is black, with a slight green iridescence, while the sides of the face, neck, throat, and chin are buff,'spotted with black, like the black duck parent. The breast shows the mallard chestnut, but much obscured and less brilliant, while the feathers of this area have a broad, black, sub-terminal pattern (pl. 9, fig. 6). The lower edge of the chestnut breast area is poorly marked off from the abdomen, not by a sharp line as in the mallard, and the white underparts have a dark sooty appearance, with the fine vermiculated pattern of the mallard showing through to some extent. The under tail coverts are mottled and intermediate in type. The whole upper surface is very close to the black duck, but the speculum of the wing has the white anterior and posterior bars of the mallard. The rump has a greenish tinge, and the sex feathers are well developed (not so much so in the first year).

The female hybrid, as might be expected, is simply a dark mallard female with no distinctive characters, as there are no striking differences between the female parents (pl. 3, fig. 5).

It is of interest to note that this hybrid is very similar to the Australian-mallard hybrid, only in this latter cross all the mallard characters are less well developed (green head, sex feathers, chestnut area, etc.). This point will be referred to again.

In 1910 this entire lot of $F_{1}$ (mallard-black hybrids) was run together, and produced six males and nineteen females. These males were kept until one and one-half years old, so as to give them a chance to develop any latent characters. The nineteen females were allowed to grow to an age of two or three months, but as they showed nothing of interest (same as $F_{1}$ 's) one was saved as a specimen and the rest discarded. In 1911 ten more $F_{2}$ males and four $F_{2}$ females were reared from the same source. This comprises all of the $F_{2}$ generation. The twenty-three females were all very much alike, and similar to $F_{1}$ females. The sixteen males must be briefly described. Out of the entire lot there may be said to be only one variate which is especially marked. This 
is a bird ( $\sigma^{7} 174,1911$, pl. 3, fig. 8) about halfway between the $F_{1}$ type and the mallard parent. This bird was kept until a year and a half old, and was tested with pure mallard females (see below). It has a very green head with dark mottling on the cheeks and sides of the neck; while chin and throat are iridescent black. There is no neck ring, but the breast is rich chestnut, slightly spotted. The rest of the lower parts are like those of $F_{1}$ males but lighter and more vermiculated. The sex feathers are fully developed, and the flanks, sides of the breast and scapulars show mallard vermiculations. Male 37 (pl. 3, fig. 7) is another variate, with slightly more pronounced mallard characters than the $F_{1}$ type. On the other hand, several, such as $\sigma^{7} 172,1911$, are darker than $F_{1}$ types. The anterior white wing bar in this last bird is absent, and there are no mallard vermiculations anywhere.

A good deal of variation is seen in the size of the $F_{2}$ sex feathers. In four cases they are absent, in five cases they are small, in two other cases they are recorded as 'medium,' and in five cases they are large. There is then a very considerable range of development of this character from pure black duck to nearly pure mallard. This $F_{2}$ generation shows a far greater range of variability than the same generation or the Australian-mallard cross. Part of this may be due to the strain of call duck introduced, but it is hardly probably that all of it is. $F_{2} \sigma^{7} 174$ is without doubt a segregate. To confirm this opinion, this male was mated in 1912 with pure mallard stock (cross G, 1912). Four males and eight females were reared to maturity, and showed by their appearance that their father was very nearly a potential mallard. Three of the males were pure mallards in appearance, but one had the anterior wing bar reduced and a few spots on the breast. The females were all pure mallards, except that in a few cases the anterior wing bar was reduced or nearly absent. When the offspring of this cross are compared with three-quarter blood mallards (see below) it is seen that they approach much nearer to mallards than do the three-quarter bloods.

In 1912 there were made two other matings in this same experiment, back crosses, producing three-quarter blood mallards. 
A male mallard was mated with two female $F_{1}$ birds (cross $A$, 1912), and a male $F_{1}$ bird was mated with two female mallards (cross C, 1912). From cross A ten males and eight females were reared, and from cross $\mathrm{C}$, nine males and five females (pl. 3 , figs. 10 and 11).

It is evident that in these crosses there was excellent opportunity for segregates to crop out, but out of the entire lot of nineteen males there are no pure mallards, and only one individual which can be called an $F_{1}$ type ( $\sigma^{\top} 506$, cross $C$ ). The results of both crosses are the same. They run from a modified $F_{1}$ type to mallard types with slightly spotted faces, reduced or absent neck rings, more or less spotted chestnut areas (pl. 9, fig. 5), darker upper parts, reduced white wing bars, and more or less coarseness and obscurity in the vermiculated areas. The sex feathers are always fairly well developed. A detailed account of this generation is not essential. Careful notes were made on each bird at maturity, and four specimens were saved.

In the same year, 1912, and also in 1913, a back cross was made between $F_{1}$ females and pure wild black duck males (pl. 3, fig. 9). Ducklings from this cross are not easy to rear, but there resulted in the two seasons ten males and eight females. These were kept until from six to eight months of age. It is difficult to say whether this lot could be picked out off-hand from a series of wild black ducks. Closer inspection shows that there is only one way that they can surely be told from pure black ducks, and this is by the pattern on the feathers of the upper chest (pl. 9, fig. 9). In all the males these feathers show, besides the terminal buff and sub-terminal black area, an inner distinct buff barring, which is further separated from the shaft by another blackish area. In the black duck parent this inner buff band is never present except in a very narrow or obscured condition (pl. 9, fig. 1). This barring is homologous to the 'eclipse' feathers on the chestnut area of the mallard's summer plumage (pl. 9, fig. 4) and is undoubtedly a mallard character (see Australian $\times$ Mallard crosses). The females cannot be certainly told from pure black ducks. There is also great uniformity in this back cross. 
The mallard eclipse breast pattern is seen in the males of those other species of black ducks which have slightly more differentiated sexes; i.e., anas diazi and anas wyvilliana and probably represents (23) a primitive sex dimorphism.

Besides this distinct mallard character in the three-quarter blood black duck hybrids reared from a female mallard, there is usually a slight tendency to a little green in the post ocular region, a slight development of sex feathers, and a darker rump, but these are not always present, and curiously enough they some-

TABLE 1

Scheme of matings: Mallard-Black duck experiment

1909 o Black $\times$ \% call duck (mallard)

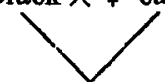

$3 \sigma^{7} 8,4 \%$ 's, all alike and intermediate

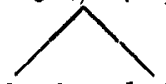

$1910-\mathrm{F}_{2} 16 \sigma^{7 / 8}$ and $23 \%$ ' $\mathrm{g}$; some variation in $\sigma^{7 \prime} \mathrm{s}$, especially in one case, $\sigma^{7} 174$

1911

1912 o 174

and

1913

1912

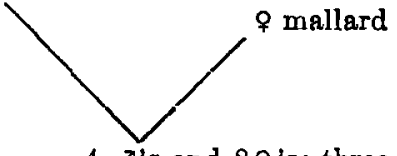

4 T's and $8 \%$ 's; three of the males and some of the females are pure mallards, others nearly so

ơ Black $\times$ \% F 1 (Black ơ $\times$ \% call)

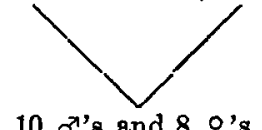

Males all to be told from pure Blacks by pattern on chest feathers. Females hardly to be told from Blacks

(Black $\times$ call)

or $\mathbf{F}_{1} \times$ q mallard

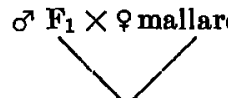

(Black $\times$ call)

o’ mallard $\times \& F_{1}(1912)$

$19 \sigma^{7} \mathrm{~s}$ and 13 \%'s

Both crosses alike. They contain no pure mallards, but several ducks nearly pure. Only one individual can be classed as an $F_{1}$ type. The females are all to be told from pure mallards by reduced or absent white wing bars. either anterior or posterior, or both. 
times occur in pure wild male black ducks (see discussion at end of Australian experiment). These very slight mallard characters would probably tend to increase a little with age, but this supposition has not been tested.

Summary. This cross results in hybrids very like the Australian-mallard crosses, but both in $F_{1}$ and $F_{2}$ and in the back cross with the black duck parent more mallard characters appear and apparently a greater amount of segregation occurs. This is probably due to the latent mallard characters present in the pure black duck. See Australian-mallard discussion, page 545. The back crosses, especially the three-quarter blood black duck series, are uniform, much more uniform than the $\mathrm{F}_{2}$ generation. Out of sixteen $\sigma^{7} \mathrm{~F}_{2}$ 's, only one segregate in the mallard direction occurred, and this bird when tested with pure mallard females produced apparently pure mallards in about half his offspring.

Back crosses never produce pure parental types except in the female sex.

\section{AUSTRALIAN-MALLARD EXPERIMENT}

Another cross between two species, only one of which is sex dimorphic

In 1909 a pair of Australian ducks, Anas superciliosa, was purchased (pl. 4, fig. 1). They were placed in a mating pen and produced seven ducklings, all of which were reared to maturity. Since that time the original pair has produced one or two broods each year, so that at least sixty of their offspring have passed through my hands, all of them proving absolutely true to type and showing no variations.

The Australian duck, a species ranging from Java through the Australia-New Zealand region to Polynesia, is a bird with rather local habits. For no very good reasons it has breen placed in the genus Polionetta. It is very plain colored, the sexes being identical, and in a general way it closely resembles our American black duck, except for the pattern on the sides of its face, which at once differentiates it. This pattern consists of a very light buff colored super-ocular streak with a broad black ocular stripe under it. Below this is another buff stripe, separated from the 
plain buff of the chin and throat by a narrow blackish line which runs from the gape to the ear coverts. The speculum is glossy green, not purple as in the mallard and black ducks, and framed both anteriorly and posteriorly by a broad black band. The legs and feet are dirty yellow, and the bill plumbeous color with a black nail. In size it is slightly smaller than the black duck and the mallard.

In 1910 two young $\sigma^{7}$ Australians were mated with two o mallards from original mallard stock (cross M, 1910), and produced four males and six females, ơ's Nos. $88,69,77,70$; ㅇ.'s Nos. 92, 83, 85, 86, 87, and 68 .

The next year, 1911, $F_{1}$ or No. 69 was mated with $F_{1}$ o's Nos. 92 and 83 (cross C, 1911). As.a result nineteen ducklings were hatched, but six died and only thirteen were reared to maturity. Of these only five were males. The females were examined and found to be all exactly similar to the $F_{1}$ females, except for a slight tendency to a difference in shade of the underparts. They need not be mentioned again. In the year 1912, ten more $\mathrm{F}_{2} \sigma^{7}$ 's were produced in the same way. In 1913 a pure Australian $\sigma^{*}$ was mated with one of the original $F_{1}$ hybrid females (cross T, 1913), and nine birds of three-quarter Australian blood were produced. These will be described later. The skins of a number of specimens were preserved.

A reciprocal cross ( $\sigma^{\pi}$ mallard $x+$ Australian) has thus far failed.

The first generation hybrids may now be briefly described (pl. 4, figs. 3 and 4). The female $F_{1}$ is remarkably like its Australian parent, and would quite easily be taken for that species by a careless observer. The bridle pattern on the face is, however, more obscured, the face being darker and more streaked, while the speculum is more purple, like the mallards. On the whole, though, there is a marked dominance of the darker Australian parent, like the black duck in the last experiment.

The four $\sigma^{\text {t }}$ hybrids are all practically alike, except for age changes to be noted further on. They show very little of the mallard except a general lightness of tone, being lighter on the underparts than the female $F_{1}$ 's. The face markings are the 
same as in the female, the upper parts are similar, but the speculum is more mallard-like in appearance, having the broad anterior white bar of the mallard fully developed while the posterior white bar is reduced. This is all the more curious because its Australian parent has a distinct white posterior bar but no anterior one. There are, besides these marked characters, a very slight indication of the chestnut breast of the mallard and a distinct darkening of the rump and upper tail coverts. There is scarcely any tendency to mallard sex feathers, but the under tail coverts are sprinkled with buffy edgings to the feathers. This, it must be borne in mind, is the appearance of the hybrid at the age of one and a half years. At two and a half years, $\sigma^{7} 77$ (pl. 4, fig. 3) has developed somewhat his mallard tendencies. His breast has become more chestnut and his abdomen lighter, the chin and throat are a rich buff, more ruddy than at first, and the buffy under tail coverts are more developed. The sex feathers are distinctly developed, while at the base of the neck, underneath, is a small spot of white, indicating the position of the mallard neck ring. It is thus apparent that age tends to bring out the mallard sex characters. Age tends to make this hybrid more and more like the mallard-black duck hybrid, which from the close color relationship between the black duck and Australian duck it should certainly resemble. As a matter of fact, however, it never develops the marked green of the postocular region or the well-developed sex feathers which are always seen in the mallard $\times$ black duck crosses, even at the first plumage. This point will be referred to later.

The first hybrid in this cross is then a bird intermediate in appearance but tending towards its darker parent, especially in the female. The secondary sex characters of the mallard become more prominent in the hybrid with age, at least up to the third autumnal moult; possibly longer. The female apparently does not change with age.

The $\mathrm{F}_{2}$ generation, comprising fifteen males, need only be briefly considered. It is not possible to answer the question as to whether they show any tendency to a segregation of parental characters. If they do, it is only a slight tendency. The most 
marked mallard variate is not nearly so mallard-like in appearance as the old $F_{1}$ bird referred to above $\left(\sigma^{7} 77,1909\right)$, but none of this generation were kept over one year. Age would undoubtedly tend to accentuate the mallard male characters as was shown for the first generation hybrids.

It may be remarked that $F_{2} \sigma^{r} 304,1911$, is rather Australian looking, and the speculum is distinctly greenish (pl. 4, fig. 7). It has, however, very distinct sex feathers and brown under tail coverts.

The anterior white specular bar tends to vary in this generation, being almost obsolete in $\sigma^{\top} 241,1910$, and fully up to a mallard standard in $\sigma^{7} 68,1910$. This tendency to variation anterior to the speculum is seen in some pure wild species of ducks (23). It can be safely said that it would take a very large series of both generations, with the individuals kept for at least three years, to conclusively round out this experiment and measure the actual amount of segregation (if such a condition exists) in the second generation hybrids. As far as this experiment has gone there is nothing to show any greater variation in $F_{2}$ than in $F_{1}$. Segregation, if it exists at all, is probably comparable to that found in the pintail-mallard crosses (a barely measurable amount).

The back cross produced in 1913 is of considerable interest. This consisted of a mating between a $\sigma^{7}$ Australian and a female $F_{1}$ Australian $\times$ mallard (cross $T, 1913$ ), as noted above. On first inspection they look pure Australian, and the females cannot with certainty be told from Australians, but the males all have the barred breast feather, seen in the three-quarter black ducks (pl. 9, fig. 10). This pattern was shown in the account of the black duck crosses, to be a mallard character, and is common also to certain other mallard-like ducks. There is also in these back cross birds a brownish edging and a brown bąring of the under-tail coverts, seen more fully in $\mathrm{F}_{1}$ 's.

In comparing the males of this cross with the males produced in the black-duck $\times$ mallard experiment a very considerable difference is found to be always present. The males of the threequarter blood black ducks always show some mallard coloring (green post-ocular regions, iridescent rump or upper tail coverts, 
more or less developed sex feathers, etc.). These characters appear in the young birds at the first adult plumage and very probably increase with age. We are thus led to the belief that the wild black duck actually contains mallard characters not present in the Australian duck, and that these are slightly accentuated by association in the zygote with characters from the mallard parent. The three-quarter blood pintail hybrid produced in the same way is not quite the same case, as both parent species are sexually dimorphic to a marked degree.

Certain variations of the black duck have received a great deal of attention from ornithologists, and space forbids a discussion of them here. It is sufficient to say that a second race of black ducks has been named on the evidence of several rather trivial characters; viz.: size, color of legs, color of pelieum, streakiness of chin, etc. Various papers in the Auk by Brewster, Dwight, and Townsend have presented the pros and cons of this case. It has been held that the larger bird with the red legs migrates later and probably breeds in a more northern region. The validity of this race is still in dispute, and its name, A. rubripes, is now thrown into synonomy and but one species recognized. I pointed out in a note on the American black ducks (23, p. 300) that male black ducks kept in confinement for three years tended to develop quite marked mallard characters. Some of these characters are the very ones which are found in the three-quarter black duck hybrids, but not in the three-quarter Australian hybrids. In other words, there is present in the wild black duck, latent mallard characters, which sometime appear with age. These characters become immediately apparent when a quarter dose of mallard is combined with a three-quarter dose of black duck. The coral red legs of many adult wintering black ducks, which have caused so much discussion, may be partly an age character. We know, however, that coral legs do not always appear with age in the black duck $(29, p .176)$. The question of the two possible races of black ducks is brought up to show that the presence of mallard age characters in the black duck makes the systematic study of its two possible races still more complicated. 


\section{BLACK EAST INDIA DUCK CROSSED WITH MALLARD}

In the winter of 1910 two pairs of the so-called East India ducks were purchased from G. D. Tilley. This race is apparently nothing but a simple melanistic derivative of the domestic mallard, and in no sense a wild species. It is a small cousin to the large black Cayuga duck, and resembles that bird in color. Both sexes are black all over, but the male has a fine metallic lustre which the female for the most part lacks. This breed is liable to show white feathers (30) especially with age, on the breast, neck ring region, and at the base of the lower mandible. In fact it is rare to get a bird that does not show some defect (white feathers) in later life, though the first plumage may be perfect. In poorer examples of the breed the mallard chest area shows through the black coloring. The race breeds perfectly true, as was amply demonstrated by my strain in 1911 and 1912; but, of course, there is variation in depth of color and metallic lustre. The eggs of this variety are a deep chocolate or sooty tint, but they grow lighter colored after the first few eggs are layed.

In order to see how this blackness behaved in crosses, a reciprocal cross was made with my original mallard stock in 1910. $\sigma^{7}$ East India $\times$ \% Mallard (cross $\mathrm{J}$ ) produced ten offspring, six of which were saved for further work, o's Nos. 72, 73, 129; q's Nos. 71, 76, 131.

In the other cross (cross H, 1910) a male stock mallard was mated with the two 9 East India ducks. Twelve birds were reared to maturity, and $\sigma^{7} \sigma^{7}$ Nos. $121,119,81$; and $\%$ ' $s 77$, 78 , and 80 were saved. As both sets of the $F_{1}$ hybrids were alike, and as both produced similar $F_{2}$ offspring, they may now, for the sake of simplicity, be treated together.

The first generation ducklings are black, except for a yellowish breast area, and sometimes an ocular yellow mark or a little yellow at the base of the bill. The adults are also black like the East India parent. Some of these hybrids are exactly as black as the black parent, but others show a slight brownish cast, especially among the females. One male (Cross J) has a large 
white chest patch and very much lighter under parts. He was not used in producing the $\mathrm{F}_{2}$ lot. The East Indian duck therefore shows almost complete domination over the mallard.

The $\mathrm{F}_{2}$ generation was reared in 1911 and 1912, In the first of these years the reciprocal crosses were kept separate, as noted above, but as it evidently made no difference in which direction the cross was made (no sex linkage) this precaution was abandoned in 1912.

The entire $F_{2}$ generation considered together shows immediately after hatching two entirely different types with a questionable third type. There are sixty-one of the dominant East India type, twenty-eight mallard type, and four jet black, so called 'freak type.' Forty-five ducklings of these three classes were reared to maturity and the rest were described in the down color and discarded for lack of space. All four of the 'freak' type were reared to maturity. The proportionate distribution of the types by years are, in the down, as follows:

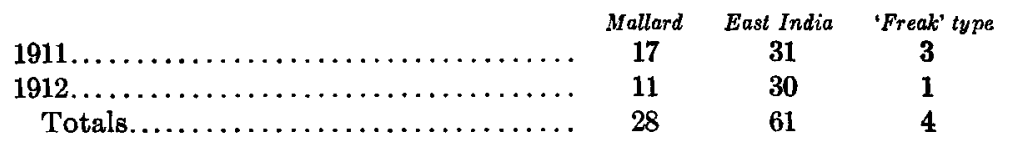

We may now consider the dominant $F_{2}$ class. These show in the down a great variety of pattern, especially about the head. The post-ocular and occipital region is in some cases much mottled with yellowish, in other cases it has the same appearance as the $F_{1}$ or the pure East Indian duckling. Moreover, the upper breast and a patch at the base of lower mandible is apt to be more or less blotched with white, and the extent of this blotching was found to be a very rough indication of the blotchiness of the adult bird. The females proved more uniform in down.

At maturity the males of this dominant class were found to present a wide range of pattern, but the females were practically true to the $F_{1}$ type. This difference in the sexes is very marked. The males fall into a nearly continuous series from a type showing a distinct mallard pattern (though very dark) to a pure $F_{1}$ type (solid black). The males also exhibit all degrees of blotching at the neck-ring, chin, and on the breast, especially at that line 
where the chestnut in the mallard ends. There is no relation between amount of blotching and general color of the bird. Some of the most mallard-like individuals are solid colored, while some of the blackest birds are heavily blotched. The mottling of the hind neck and post-ocular region, so common in the down plumage does not appear in the adults except very slightly in two cases. This diversity of the males is without doubt due to heterozygosis, but this point was not tested.

An examination of the recessive (mallard) class of $F_{2}$ 's shows them to be all alike in down, being very close to the mallard ducklings, but always, or nearly always, with a slightly broader and darker ocular streak. On maturity these birds are pure mallards to the casual eye, but close inspection reveals the following points. The males, only four of which were reared, are usually to be distinguished by a very slight sooty appearance of the lower abdomen, which in one specimen, No. 411, is quite pronounced (pl. 6, fig. 3). Two of these males would certainly not be noticed as being in any way peculiar (pl. 6, fig. 4). The females, however, are all slightly 'contaminated' by the cross, as is seen from their darkened appearance, both above and below, and the very distinct sooty look to the lower abdomen (pl. 6, fig. 5). The third or freak class, which must also be regarded as recessive (see below) is always jet black in down, like the 'freak' mallards described in the 'freak mallard' experiment. There are three males and a female. The males are darker on the back than the pure freak males, and one of them, No. 160, 1911, has a little area of chestnut below the neck-ring. The appearance of this slightly contaminated freak type is not easy to explain. One of these freak males (No. 207, 1911) was tested in 1912 with the mallard stock (cross I, 1912), and produced nine males and six females. There were among these no freak types. In down plumage all were of mallard coloring with somewhat darker ocular stripes, like the recessive mallards from the $F_{2}$ East India cross. When adult three of these males were not to be told from mallards, while six had the slightly sooty abdomen. The females were darker than mallards and many had the anterior white wing bar reduced or absent. In 
fact the birds of this lot are just like $\mathrm{F}_{2}$ recessives, and the freak type has been entirely dominated. This shows that this type must be classed as a recessive, and probably was introduced into the cross as a recessive character from the mallard side.

The dominant $F_{2}$ 's need not be further considered, as they were not tested. It was desired to test the contaminated recessive female $\mathrm{F}_{2}$ 's, and two of them (Nos. 202, 184; 1911) were mated to a male mallard (cross M, 1912). From this cross there resulted twelve males. Seven of them are classed as pure mallard type and four of them as sooty mallard type (sooty on lower abdomen, sometimes slightly darker above, anterior wing

TABLE 2

Scheme of matings in Black East India $\times$ mallard experiment

$1910 \sigma^{\pi}$ mallard $\times q$ East India (cross D) $\sigma^{\pi}$ East India $\times q$ mallard (cross F)

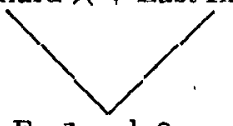

$F_{1}$ or and o nearly

black all over

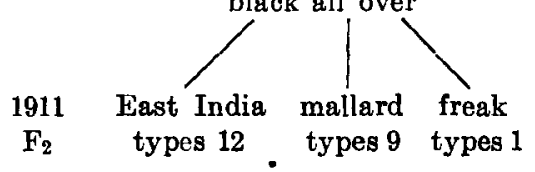

$1912 \quad F_{1} \sigma^{7} \times F_{1}$ 우 regardless

$\mathrm{F}_{2}$ of reciprocal matings

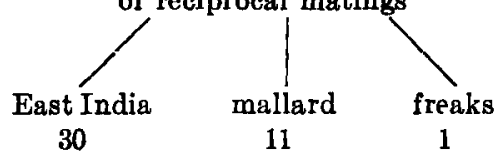

1912 Freak ơ $\times$ mallard $\%$

$$
9 \sigma^{7} \sigma^{7}, 6 \% \text { \% }
$$

No freaks-offspring like

$F_{2}$ mallard types (recessive)

1912

ণ mallard $\times$ ㅇ $F_{2}$ extracted mallards

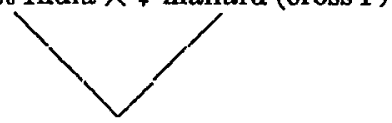

$F_{1}$ same as reciprocal

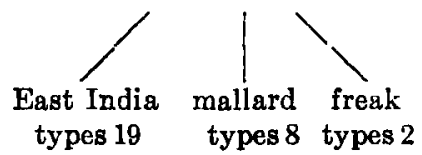

$12 \sigma^{x} \sigma^{x} ; 7$ pure ma lard

4 sooty mallard, 1 freak 
bar sometimes reduced). The remaining male is a pure freak type and was jet black in the down, as this type always is ( $0^{7} 455$ ). The females were not all carefully examined, as they were discarded for another purpose. The only specimen saved is practically a pure mallard with the wing bars both present. The 'contaminated' females of the $F_{2}$ recessives therefore passed on to about half of their male offspring, the contamination character (sooty abdomen, etc.), but the peculiar freak type also appeared again in one case.

\section{FREAK MALLARD EXPERIMENT}

In the spring of 1909 one hundred and twenty-five mallard eggs were purchased from George Edgar, gamekeeper of Tranquility game preserve in Connecticut. From this lot sixtyfive birds were reared to maturity, forming the basis of mallard stock described elsewhere.

At hatching time two of these ducklings appeared so remarkable in color that they were banded. They were coal black. One of them died, but the other, or No. 39-256, matured, and was found in October 1909, to represent a new type of mallard, a clear-cut variation, which I have called 'freak mallard' (pl. 5, fig. 3). This male can be described in a few words. There is entire absence of white neck collar and chestnut breast area, the silver color of the lower parts extending up to the green of the neck, while the speculum is dull black instead of metallic green. No other duckling in this lot showed any departure from normal.

In 1910 o $^{7}$ 39-256 was placed in a mating pen with a normal o mallard from the original lot, and seven ducks were reared to maturity, $\sigma^{7} \sigma^{7}$ Nos. 116 and 145 and $\circ$ o Nos. 114, 117, 93, 115, 118. They were all normal mallards, the freak character proving entirely recessive.

In 1911 one of the $F_{1}$ males and two $F_{1}$ females were mated (cross E, 1911) and there resulted five black 'freak' ducklings and seven normal ones (pl. 5, figs. 5 and 6). Only two of the freaks lived and these were both females, but when adult they were seen to be different from mallard females. They are always to be 
told by absence of the dark ocular streak and the light supraocular streak, and presence of a dark, streaked throat, which in the normal bird is plain buff color. The throat in the female freak is exactly like its cheeks (pl. 5, fig. 4). These 'freak' mallards appeared to lack vigor and were by no means easy to rear.

In 1912 \& $\odot$ Nos. 221 and 219 were mated with the original freak $\sigma^{x}$ (cross $\left.N, 1912\right)$, and there were reared five birds, three males and two females, all typical freaks, showing that the freak character had segregated in a pure state. In 1913 this generation gave rise to still another one (cross $R, 1913$ ) all similar in character.

It is interesting to note that out of thirteen freak ducklings hatched in 1913, only seven were reared. Two female freaks in 1913 laid only forty-one eggs. Twenty of these 'were set, but only thirteen hatched. The English stock mallards on the other hand lay about forty eggs each, and these eggs are 80 to 100 per cent fertile.

I have failed to find any evidence of this 'mutation' occurring in wild killed birds. Dewar and Finn (6) mention its occurrence in domestic mallards, and Rogeron (27) reared many of them. Rogeron thought that he obtained his freaks from pure wild stock, but of this I think there may be some question, because the breeding European wild stock seems to be rather strongly given to variations and contaminations, as Rogeron's own book shows. It is, however, possible that this variation does occur in European wild mallards; it certainly does not in American wild killed birds. This freak variation is common in the ducks of the London parks, as I have noticed myself.

Besides the characters above-mentioned, there is often a reduction of the white speculum bars in the female, and generally a darker look all over in that sex. The first juvenile plumage of both sexes is said by Rogeron to be more uniform, a point which I did not notice. The downy young are always black all over, including the bill, legs, and feet.

This is an exceedingly clear-cut mutation, and has showed no tendency to vary in my stock. Finn (7) mentions seeing gray- 
breasted birds with a very little chestnut at the base of the neck, but no such intergrade has appeared here.

This freak condition may be of the same nature as the socalled Chrysolophus obscurus, the dark form of the golden pheasant, which was at one time thought to be a new species. It apparently segregates out clearly in aviary strains of golden pheasants but is never found in the wild.

We thus see that although the chestnut breast and white neck ring of the mallard are inherited in a very complex way when crossed with other species, there nevertheless exists some 'modifier' or other single factor whose presence is necessary for their expression. Also we have every reason to believe that the loss of this 'modifier' is associated with relative sterility and lack of vigor.

TABLE 3

Matings in 'Freak Mallard' experiment

English mallards, about 500, including three freaks

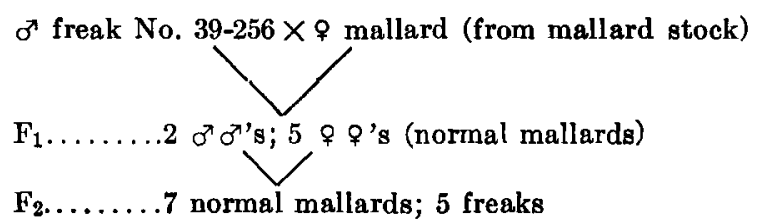

$\sigma^{7}$ freak No. $39-256 \times \& F_{2}$ freaks

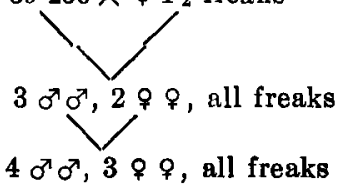

Prince of Wales (Phasianus principalis) crossed with ring-neck pheasant ( $P$. torquatus)

This cross was started with the idea of testing the inheritance of the white neck-ring of torquatus. All the true pheasants (4) may be roughly divided into four groups, according as they have, or have not, a white neck ring, or according to whether they fall into the green rumped or the red rumped group. By 
far the largest group of these four possible combinations is the red rumped dark-neck (no neck ring) group; and into this falls principalis. This group contains 9 species and 5 sub-species. The next group, the combination of red rump and white collar, is a very small one. It contains but 2 species and 1 sub-species. The green, gray, or slaty rumped group with dark necks number 8 species and 2 sub-species, while lastly the green rumped and white necked group contains 4 species and 3 sub-species. There may be said to be therefore a tendency in nature towards a combination of red rumps and dark necks and green rumps and white neck rings. It was thought of interest to test the question whether an association of these characters would be found in hybrids. It has been shown above that in duck hybrids, for instance, the mallard characters, green head and chestnut breast, are always correlated in their intensity.

The striking features about the principalis, or Prince of Wales, pheasant are as follows: Neck ring absent, lesser and median wing coverts white, with white shaft stripes on the greater coverts; rump and upper tail coverts orange red with a few fine black dots; tail - barring reduced to faint lines. Torquatus or ringnecked pheasant: White neck ring well marked, though absent ventrally; rump greenish to greenish slate, with sub-terminal bars of brilliant green; lesser and median wing coverts mostly sandy buff color; tail barring very marked, especially towards the tip, where black areas from 6 to $12 \mathrm{~mm}$. wide occur. There are other differences between these species, especially in the mantle, in the flanks, and in the metallic color of chin and throat, but they are characters rather too subtle for the present study.

In 1909 a pair of pure wild principalis pheasants were secured from Wallace Evans, Oak Park, Illinois. The male was carefully compared with a wild killed skin from Merv, Trans-Caspian, Asia, collected in June, 1889 (pl. 7, fig. 1). The two birds agreed very well, and there was only one slight difference, the tail bars on my live specimen being fainter than those of the Merv skin (a principalis character). The rump also is redder in my skin, but taken as a whole the differences between the two birds are no more than individual or seasonal. 
The ring-necks or torquatus used in this cross belong to a strain from which at least two hundred individuals have been reared on the farm. In no case was the white neck ring absent (pl. 6, fig. 2).

From the original pair of principalis there were reared in 1912 and 1913, thirty-three pure bred offspring, none of which showed any departure from type.

In 1910 the original male principalis was mated with two females from my torquatus stock. From this pen I reared four males and five females, which may be described as follows (pl. 6, fig. 3). Males: neck ring reduced but present; wing coverts grayish white, not so white as in principalis, white area less than in that species; rump rich reddish chestnut, not the gold red of principalis or the greenish slate of torquatus; tail barring very narrow, showing partial dominance of the principalis parent. In all other respects the hybrids are intermediate. The female is much lighter colored than the torquatus female, and quite near that of principalis.

In 1911 mating was made, with a trio of the $F_{1}$ generation and resulted in the rearing of ten $F_{2}$ males and a number of $F_{2}$ females. The latter were killed as soon as they could be sexed, on account of lack of room.

These $F_{2}$ males all had the neck ring, though in one case it was reduced to a few white feathers. They were graded in an arbitrary manner with relation to the four characters described above, neck-ring, wing-coverts, rump, and barring of tail. The result obtained is shown in table 4.

There is, as far as can be determined with small numbers, no correlation between any of the above characters. They are distributed regardless of individuals. For instance, the nearest approach to a principalis is specimen $D$, which has a small neck ring, a very red rump (much darker color, however, than principalis) white wing coverts, but the white patch reduced in area, tail barring intermediate. The mantle and the throat in this bird approach somewhat the principalis color pattern. To sum up the series, there is a very distinct segregation of the characters considered, but no clear dominants or recessives appear. Very 
TABLE 4

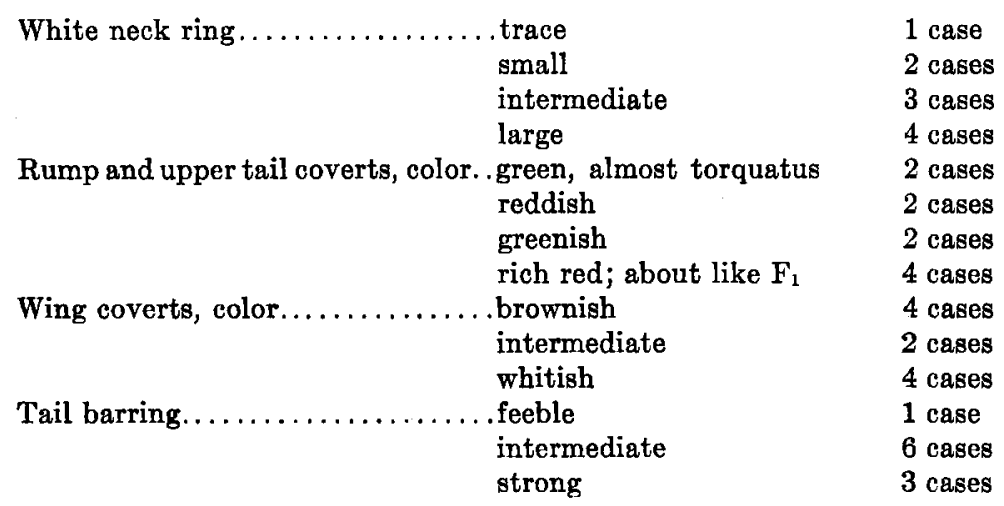

large numbers would be of interest in this cross. The tendency to segregation is probably greater, than in, for instance, the pintail mallard duck hybrids (pl. 6, figs. 6-10).

In 1912 (cross $\mathrm{E}$ ) the original principalis male was mated with two $F_{1}$ females and fifty-four chicks were hatched. Unfortunately a severe enteritis broke out among these birds before they were mature and only nine males were left available for study in November (pl. 6, figs. 4-5).

Comparing these back cross birds with $\mathrm{F}_{2}$ birds the following generalizations are at once to be made. These nine threequarter blood principalis are all to be told at sight from the ten $\mathrm{F}_{2}$ by the very marked white wing coverts. The white area is whiter and of greater extent in all cases. There is no marked segregate, the lot is fairly uniform. The upper back and mantle is lighter in all cases except in No. 829, where it can be nearly matched with specimen $\mathrm{F}_{2} \mathrm{D}$. The neck ring runs from zero in No. 586 through two other specimens which have only one white feather each, to No. 835, in which there is a very narrow ring (about $5 \mathrm{~mm}$.) present on sides only. The tails of these back crosses are all very narrowly barred, more so than in any $F_{2}$, except in one case, No. 586, which matches $F_{2} A$. The rumps are all red; they are more golden red than the $\mathrm{F}_{2}$ rumps, the least red, No. 582, matching exactly the reddest $F_{2}$ rump (spec. D) 
There is then an approach, perhaps even an overlapping, of individual characters between the $F_{2}$ 's and the three-quarter blood principalis, but this does not refer to individuals, which, all characters taken together, never approach each other in the two series. The uniformity of the back cross is interesting. It is like the uniformity of the three-quarter black ducks, threequarter Australians, and the three-quarter blood mallards.

To anyone familiar with pheasants there will at once be a query, was the torquatus stock pure? This is a criticism which cannot be lightly disregarded. The English pheasant was, as is well known, originally pure colchicus from Asia Minor, a ringless pheasant with sandy brown wing coverts, red rump and upper tail coverts, and wide tail bars. Nearly pure specimens of colchicus may be even now occasionally seen in English markets, but they apparently all have the green terminal bar on the rump feathers, characteristic of torquatus. If the ring-neck contains blood of colchicus sufficient to effect an increased segregation in hybrids with other species, the neck ring and the rump color should be the regions most affected, for these are the most sharply contrasted in colchicus and torquatus. Such, however, can hardly be said to be the case. It is intended to test this point in crosses between principalis and other species, but for practical purposes the ring-neck can be considered a fixed race. Ghige has also reached the same conclusion.

To sum up: This cross gives intermediate hybrids with a tendency to a mild form of segregation in $F_{2}$, this segregation occurring without apparent correlation of parental characters. The most extreme $F_{2}$ characters varying in the direction of principalis exactly meet the three-quarter blood principalis series. The three-quarter blood series is more uniform than the $F_{2}$ series, and does not overlap it. It is probable that threequarter blood birds can always be told from $F_{2}$ birds, although some individual characters may be the same in the two series. 


\section{INHERITANCE OF SPOTTING AND ALBINISM IN PHEASANTS}

In 1911 I received as a gift a male pheasant, of the ordinary torquatus, or English stock, a partially white male bird (pl. 8, fig. 1). The head is mottled with black, and the lower back, rump and wing coverts are very much mixed with white. The primary quills are mostly white. The lower parts except the abdomen, are nearly normal, while a part of the mantle is also nearly normal.

I mated this pied bird with my ring-neck stock in 1911, and reared one setting of eggs, all normal ring-necks (cross $G, 1911$ ). In 1912 and 1913 a trio of these $F_{1}$ 's was mated to produce an $F_{2}$ generation. The results of the two years added together are as follows: 68 normal chicks; 22 white chicks. All chicks that died in the shell are included in these figures, which are of course a perfect Mendelian result. The original male died in September, 1911.

These white $F_{2}$ pheasants were very delicate and many died young. Only eight of the twenty-two were reared, though the greatest care was taken with them. Cronau (5) obtained white pheasants, and found white entirely recessive. He had great difficulty in rearing his white birds. Whites and partial whites crop out in many stocks of English (torquatus) pheasants, but are usually destroyed as being inferior for show or sport.

Now as to the coloring of this $F_{2}$ generation of whites: They run all the way from a bird about half white, as in 784, 1912, or 1178,1913 , to pure white birds with very slight brown ticking here and there, as in $\% 780,1912$, and $\sigma^{7} 781,1912$. The eyes are always a dirty bluish gray, some a little darker than others, but not at all the bright hazel brown of the normal bird. The legs and bill are very pale pinkish.

A selection was made from the whitest birds, and in 1913 a trio of them (all nearly immaculate) was mated (cross D). The mating resulted in an $\mathrm{F}_{3}$ generation of eleven mature birds. They were all white, or nearly so. The brown ticking when present occupied a patch on the occiput, a few feathers in the wing coverts, or a little brown streaking of the flanks and breast 
(pl. 8, fig. 2). One or two of the birds had a creamy appearance all over.

A selection has been made of the darkest $F_{2}$ birds, and it is hoped to rear large numbers, with the idea of seeing whether these pied recessives may by any possibility throw a dominant (normal) individual. It is of course always possible that inbreeding of this sort will end in the loss of the stock, as pheasants seem to be very susceptible to its dangers.

Summary: Spotting behaves in pheasants as a unit character. Selection of the whitest $F_{2}$ birds produces an $F_{3}$ generation which is far in advance of the $\mathrm{F}_{2}$ 's in 'whiteness,' though some regression occurs.

Lady Amherst (Chrysolophus amherstiae) and gold pheasant (Chrysolophus pictus) crosses

In this experiment, which was begun in 1911, I planned to make reciprocal crosses, carry them to $F_{2}$ and make all possible back crosses between the two $F_{1}$ generations and both sexes of both parents, in order to detect any trace of sex-linkage. This entailed twelve matings, rearing of the males until fourteen months or more of age (full plumage is not assumed till late in the second summer in either of the parent species) and inbreeding species made delicate already by many generations of aviary life. The greatest difficulty encountered, however, was the fighting propensity of the males, which were being held over for full plumage. This necessitated placing each male in a separate cage from early in the spring to at least the following August. This experiment has taken up much room, and progress has been extremely slow. There has been great mortality among hybrids; often as many as half or two-thirds of the young birds have died in a summer, probably on account of lack of space and crowding on soiled ground. However, nearly all the crosses have been carried out, though not. all the birds are matured enough for study.

In regard to back crosses. it is yet too early to speak, but the two series of $F_{2}$ present a feature that is so remarkable that it seems best to record the phenomena at this time. 
There were in all a very good series of seventeen $F_{1}$ males raised from both reciprocal crosses, and these were found to be always alike. An excellent plate of this hybrid is given in Elliot's monograph of the Phasianidae. There is a slight amount of variation in the yellow area on the sides of the breast, representing the demarcation in the Amherst between the green breast and the white belly. All other features are constant so far as my observation goes. We need not take time here to describe this hybrid in detail.

There are now available for study nine $F_{2} \sigma^{7} \sigma^{7}$ from the cross $\sigma^{\pi}$ Amherst $\times \&$ gold, and seven $F_{2} \sigma^{\pi} \sigma^{\pi}$ from the cross $\sigma^{\pi}$ gold $\times$ \& Amberst.

The first series, with the Amherst for male parent, is far closer to the golden type than the companion series with gold for male parent. This apparently means that the male Amherst has passed on to his progeny less of his own male characters than the female Amherst has passed on to her progeny. It is also to be remarked that the $\sigma^{7}$ gold and $q$ Amherst $F_{2}$ 's are very close to the $F_{1}$ 's, though more variable, while the other series is very much removed toward the golden type and also varies around its own mean. The two series about meet, but do not overlap in the least. The differences are marked ones, such as: color of mantle, color of crest, color of upper tail coverts, presence or absence of Amherst green on the upper breast, presence or absence of yellow area at breast-belly junction, etc. It is difficult to see how there could be any mistake in this experiment. The results appear to be clear-cut in every case. They might, however, be criticized on this score: that the male Amherst used in the cross contained golden blood, or that perhaps the $q$ gold contained a little Amherst blood. The most likely contamination is no doubt to be looked for in Amherst stock, as this is a rarer and more delicate species. But the golden blood, if present at all in the Amherst strain, must be very small in amount to escape close inspection, and it seems impossible that it could be responsible for the clear-cut difference described above. Gighi (17notes that the aviary Amhersts have been developed by cross) ing with gold and back crossing with male Amhersts until all 
golden blood was swamped. He himself crossed back to Amherst. several times. In the second back crossing (gold blood $\frac{1}{8}$ ) the offspring, he says, are pure Amherst, except for slightly broken transverse bars on the tail and slightly dim tail patterns. In the fourth or fifth back crossing all trace of gold blood vanishes. The tail characters are the last to disappear.

I feel sure that if my stock specimens of Amherst contained golden blood, it was less than one-sixteenth in amount.

The best argument against the contamination theory is that if the male Amherst had had a dose of golden blood, his $F_{1}$ hybrids would have been different from those of the reciprocal cross. This has been found not to be the case. The $F_{1}$ and $F_{2}$ $\rightarrow$ are apparently all alike, but for lack of space they have been discarded early.

It is planned to test again the question of the unlike $F_{2} o^{x} o^{x}$ with carefully inbred strain of the parent species, which are now available here.

TABLE 5

Matings described above

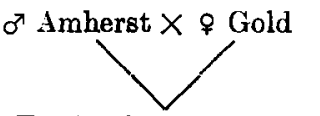

$\sigma^{7}$ Gold $\times \&$ Amherst

$\mathrm{F}_{2} 5$ 0's: 8 \%'s

$. \operatorname{similar} . .$.

$\mathrm{F}_{2}$

$F_{2} 9$ o's's, about like $\frac{3}{4}$ blood

golden and showing very

little Amherst as a series,

but some variation

\section{OTHER WORK ON PHEASAN'TS AND DUCKS}

It is now necessary to review some of the important features of the work of Alessandro Ghigi of Bologna. Professor Ghigi has made very extensive studies with hybrids of the pheasant genera Gennaeus and Phasianus. He also worked with the guinea-fowls and with fowls and pigeons. His early work was undertaken with the idea of getting at a more rational classification of the groups involved. He thought the present method 
of classifying species upon secondary sex character of plumages was not natural, and he laid stress on the phylogenetic character of plumages in females and young birds. He also showed the importance of ecologic factors in determining fertility and sterility in hybrids, and he showed that there was as a rule a typical difference in the plumages of fertile and sterile hybrids among pheasants. In fertile hybrids the male characters were more or less intermediate between the parental types and tended to produce new and more or less stable hybrid forms. In sterile hybrids there was a distinct tendency to a reversion to the more primitive plumage of the female or young, or to the assumption of characters uncommon to either parent.

Many of Ghigi's conclusions are drawn from a study of the Gennaeus pheasants, a large genus of which, the silver pheasant, G. nycthemerus, is a typical and familar example. A brief notice of his work is necessary, especially as this work has not been given the recognition which it deserves (13).

After a systematic survey of these pheasants, twenty-seven species of which are recognized (some of very doubtful value), he goes on to describe the various hybrid combinations which he obtained between the species nycthemerus, horsfieldi, lineatus, and muthura. He obtained besides $F_{1}$ 's several back crosses and complicated hybrids combining three or four species. Some of these will be mentioned again in considering segregation of specific characters. He then goes on to ecmpare the characters of these hybrids with the various wild species which are closely crowded into Burma, Southeastern China and the Shan states. The characters under consideration are very numerous and complex, but chief among them may be mentioned the mantle pattern, the color of the fringe on the lower back and rump, shaft markings on feathers of sides, pattern of middle tail feathers and color of legs. He recognizes fourteen more or less opposed characters in the males and nine in the females. From this consideration he takes the position that the G. affinis of Oates is a hybrid with blood of $\mathrm{G}$. horsfieldi predominating, and containing a trace of lineatus. G. andersoni and G. belli can be interpreted as hybrids, near to lineatus, but with the red legs 
of the silver pheasant, and so on. In all, ten species are accounted for in this way.

Ghigi next considers the distribution of the group, and shows that most of the recently described species occur in the region where the horsfieldi, nycthemerus, and lineatus converge toward central Burma. The species of the genus overlap very much more than the true pheasants, no two species of which are supposed to be found in the same region.

The last part of this work is composed of general considerations in regard to the dissociation of specific characters and a comparison between these characters and some of the ordinary racial characters seen in domestic products. In general it is maintained that crosses amongst systematic species (of phasianidae) where fertile hybrids are obtained, lead in a definite way to new stable forms in which characters prevailing in the parents are associated in a different way. He does not give this conception as in conflict with Mendelism, but regards the sum of specific characters as decomposable in several unities, which are destined to separate themselves in the successive generations after the first crossing. The species characters cannot often be classified as antagonistic pairs but as a complicated series often in correlation, but capable of being broken up so that in some cases pure characters appear. He would distinguish between those species which produce new hybrid combinations and retain their hybrid characters in further crosses, and those species which cannot produce new types in hybrid combinations, and always tend to assume parental forms when back crossed; in other words, Mendelian disjunction. For example, leucomelanus $\times$ horsfieldi and leucomelanus $\times$ lineatus produce intermediate forms, and on further crossing, new stable combinations, because the parents differ in their character complexes. On the other hand, leucomelanus $\times$ muthura and leucomelanus $\times$ albocristatus cannot give rise to new forms, for they differ in single undecomposable characters and their products tend to resume parental types. Muthura has a black fringe and a steel blue rump, albocristatus a whitish fringe and rump widely spotted with white; leucomelanus has the fringe of muthura and the rump of albocristatus, etc. Under this class also comes the Amherst-golden combination, for these 
species differ in certain clean-cut antagonistic particulars and their back crosses tend quickly to resume parent types (17, p. 236). In other words, Ghigi, would consider the first category of parents as elementary species, and the second category as varieties. The really primitive species he considers as sterile or partially so, and always able to maintain themselves in the wild. It is obvious, however, that no such classification as this can be strictly enforced. No parental types (as far as the work of Ghigi, Mrs. Haig Thomas, and myself has shown) are ever entirely reached by the first back cross, at least not in the males, though it may be argued that in no species crosses of birds have numbers sufficient for such a result ever been reached. Furthermore, primitive species do not always produce sterile hybrids, as Mrs. Haig Thomas has shown for nyethemerus and Swinhoii (20).

We may now return to that part of Ghigi's work which most concerns us, the measure of 'variability' induced by crossing wild species. Ghigi himself did not pay much attention to this point, and did not attempt to raise large numbers in his pheasant crosses. For theoretical purposes it would have been interesting if he had restricted his efforts a little more to certain typical hybrids. In the work on the Gennaeus pheasants which we have been considering, among the list of hybrids we note that $\sigma^{7}$ (nycthemerus $\times$ muthura) $\times$ o nycthemerus produced two males half-way between the first hybrid and pure nycthemerus, but one of them had red legs. The female was indistinguishable from pure nycthemerus. of G. horsfieldi $\times$ \& (nycthemerus $\times$ horsfieldi) produced four $\sigma^{7}$ 's and three ${ }^{\prime}$ 's. One $\sigma^{7}$ was like horsfieldi except the white fringe on his back was narrow, and the tail was nearly black. The second differed in having brown spots on the external margin of the first ten secondaries, hardly any white fringe, middle tail feathers striated with white and brown, and with other differences (specimen not entirely developed). The third had a tail like the last, but white stripes on several feathers of the sides of the neck, a large white band on feathers of rump and remaining parts like No. 1 . In the fourth male there appear to be several distinct differences: Crest shining black and nuchal area black; lower parts blue-black 
like crest; back black with a few white stripes; scapulars and wing coverts black with three or four pairs of pure white stripes; middle tail feathers vermiculated on internal web, white on base, etc. Two of the females of this cross show variation, and one is the same as pure horsfieldi.

In cross

$$
\frac{\left.0^{x} \text { (nyc. } \times \text { muthura }\right) \times \text { nyc. }}{\% \text { (nyc. } \times \text { horsfieldi })}
$$

there were two males and two females. The males differed in the period of the assumption of the secondary sex characters. One of the females had red legs. In cross

$$
\frac{\sigma^{\pi} \text { lineatus } \times \% \text { (nyc. } \times \text { muthura) }}{\text { o horsfieldi }}
$$

there were two males and four females and both sexes showed numerous differences. In cross

$$
\frac{\left.\sigma^{7} \text { (lineatus } \times \text { muthura }\right)}{O \text { (nyc. } \times \text { muthura }) \times \text { lineatus }}
$$

there were four males and two females; two of the males were the same and the other two differed, one being delicately striated above; females alike.

In considering these hybrids it is very essential to recognize the delayed secondary sex plumage which I myself have often seen, and which Ghigi mentions in several places. If this is not taken into account, variations will often be overestimated. This precaution Ghigi has apparently understood. The best case of segregation is found in a recent publication of Ghigi (17), which considers the cross $\sigma^{7}$ horsfieldi $\times \propto$ ( $\sigma^{7}$ nyc. $\times$ \% horsfieldi). He had twelve males; six of them were almost like horsfieldi, but differing a little from that species; the other six hybrids are variable and form a series from the $F_{1}$ hybrid type to nearly pure types, black like horsfieldi but striated on the back, wings and tail. This last result he considers at variance with much of his other work, but it is clearly a case of segregation, more pronounced than any obtained in my experiments.

On the guinea-fowls Ghigi's work is closely parallel to that on the Gennaeus pheasants (15). He concludes that of the seven- 
teen species and sub-species, only about half are to be considered as the products of change or variation. The rest are forms derived from natural cross-matings.

With the true pheasants Ghigi has traced the geographical range of certain characters, neck ring, red or green rumps, etc. $(18$, p. 69$)$, and speaks of the true pheasants as reducible into certain well-defined groups. As evidence of the stability of hybrid forms he mentions the hybrid combinations in hunting preserves. For instance, in parts of England the versicolor and colchicus has resulted in a green-backed pheasant, on the Continent combinations of versicolor and torquatus have resulted in a stable variety, the green, ring-necked pheasant. Other stable types of introduced pheasants can be readily adduced. The ring neck of Massachusetts shows very little variation, and yet it has a hybrid origin.

In working with pigeons and with the wild gallinae (a cross was made between a $\sigma^{7}$ sonnerats jungle fowl and a series of farmyard hens) Ghigi reaches the conclusion that both pigeons and fowls have had a polyphyletic wild origin. In pigeons, leuconotis, rupestris, and livia; in fowls, sonnerati, laffayettii and Gallus gallus (14) (17).

Ghigi has described a very interesting mutation from a pure strain of Swinhoe pheasant (11), which he believes to te the 'door' of a new variety. He. also cites the so-called Bohemian pheasant as a mutant from colchicus (mentioned by Tegetmeier) and other indications of spontaneous change in this group.

In his later publications Ghigi is inclined to include hybridism as a direct stimulation to actual change $(18$, p. 84$)$. For instance, when the sonnerat's jungle fowl $\sigma^{T}$ is crossed with ordinary hens of the farm-yard, the scaly and barred wing coverts of the wild male vanish and do not reappear in further crosses. Such a character is held recessive, but Ghigi thinks it may perhaps manifest itself as a stimulus to change.

As far as sex-limited characters are concerned, Ghigi has not reported on reciprocal crosses. In his pheasant crosses (particularly the back crosses) he finds no real evidence of paternal or maternal influences and in all crosses where a certain domi- 
nance is apparent he prefers to attribute it to a species character rather than to unequal sex transmission $(13$, p. 39). This would appear from my work to be the proper view, except that I have found an exception in the unlike reciprocal $\mathrm{F}_{2}$ Amherst $\times$ Gold crosses and in the sterile reciprocal hybrids Reeves $\times$ torquatus (26).

Mrs. Haig-Thomas found (20) that in crossing $\%$ silver (nycthemerus) pheasants with $\sigma^{7}$ Swinhoe that in the $F_{1}$ 's crossed back to the $o^{7}$ Swinhoe, the o Swinhoe plumage appeared in a pure state. Also in this back cross she obtained a pure $\sigma^{7}$ Swinhoe and three hybrid or impure or Swinhoes. In other words, there seems to have been some variation among the males. She concluded that the $\sigma^{x}$ Swinhoe was a heterozygote for sex.

It is interesting to note that Ghigi found silver $\times$ Swinhoe hybrids always sterile (9), though the females laid eggs. My own $F_{1}$ hybrids from this cross are thus far partly sterile.

In another experiment Mrs. Haig-Thomas crossed (21) $\sigma^{7}$ versicolor and $q$ formosans. She then back-crossed one of the o hybrids to a $\sigma^{7}$ versicolor, and obtained five females and two males. All the females were alike and very close to versicolor. The males (only two) showed some formosan characters. This was the same result as in the previous Swinhoe-silver cross.

Recently (22) the same writer has described further her work with the progeny of a cross $\sigma^{7}$ Swinhoe $X \%$ silver pheasant. She mated an $F_{1} q$ back to a silver $\sigma^{7}$ and one of the resulting females was again mated back to silver. In this generation of seven-eighths silver blood there appeared two birds, a male and a female which showed new characters and were called mutations. This pair was mated and produced another lot of ten birds somewhat like their parents. This p^sper is confined almost entirely to the plumage of the female hybrids.

It may be remarked that the elements of this cross are very numerous. First, both the males and the females of the parent species differ widely. Second, the males assume adult plumage only in the second year and have a distinct primary plumage unlike the female, this being especially marked in the case of the 
Swinhoe. Thus we have six different plumages and their transitions to consider. Furthermore, although Mrs. Haig-Thomas does not appear to have encountered it, partial or complete sterility occurs in these hybrids and if present would without doubt effect the adult plumages (retard them).

The following points only can be noted. No pure silvers were obtained, either male or female, in the second back cross to silver male (seven-eighths silver). Female Swinhoe characters were transmitted by the Swinhoe male through four generations without addition of Swinhoe blood. The so-called mutants of the third generation produced offspring mostly like themselves and the females were different from any others in the whole series. There was, however, some sort of segregation among these ten birds and traces of Swinhoe parentage could be traced.

Mrs. Haig-Thomas finds a condition in some of these hybrids which she calls 'pattern transference' the transference supposedly of certain markings from one area to another or even from one sex to another sex. For instance, a pattern on the breast of one of the female hybrids looked like the flank pattern of the young male silver in transition plumage. The evidence for this interchange of patterns between the sexes seems hardly strong enough in this case, for the possibilities of variation and reversion are too great to be ignored.

Evidence is brought forward of two distinct breast and tail patterns in the females of silver pheasants which seem to occur both in aviary and wild shot birds. It is not a clear-cut dimorphism, but it might very easily further complicate this cross.

Among ducks there is a very large number of described hybrids, some sterile, others fertile, but very little genetic work has been done on wild forms. In 1905 (2) J. L. Bonhote reported upon a series of complicated matings between the mallard, the pintail, the spot bill, the Australian duck and Meller's duck. Although it is impossible to deduce any genetic facts from these matings, there are some interesting points in this work. In the second and third generations of Bonhote's 'trigen' and 'tetragen' combinations there was a distinct tendency towards certain types, and never variation enough to obscure the type to which the hybrid 
belonged. Moreover, there occurred a sort of dimorphism in two cases (a dark and a light variety) which deserves notice. Two crosses were made as follows:

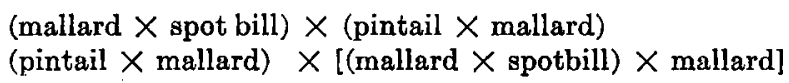

The results in these two crosses and in their offspring bred together seem to be the same. Both of them give rise to a light and dark form which is always apparent in infancy and affects both sexes. The dark form has more mallard characters, the light form more pintail. Inbreeding has only been possible with the light form, which has produced in the third generation a very light-colored bird looking like the eclipse plumage of the first generation. Mallard characters are still present in the color of the chest and in the curly sex feathers of the tail. This third generation was very weak, and probably some of its 'eclipse' characters was due to partial or complete sterility. The tendency for these hybrids to vary along certain definite lines is of interest in considering the theory of Ghigi in dealing with complex species hybrids; that is, that there is present in species a tendency to certain definile stable hybrid combinations, not a mere shuffing of characters.

Another of Bonhote's crosses was the mallard-spot-bill-Australian hybrid. The drakes fall into two classes, differing in the amount of mallard which they contain, and the second generation male hybrids lose some of their male secondary sex characters as in the last case.

In 1909 (3) Bonhote described a remarkable duck, almost pure mallard, which originated from a fifth generation complex of spotbill, pintail, mallard and Australian. This bird contained 50 per cent Australian, 25 per cent mallard, $12 \frac{1}{2}$ per cent pintail, and $12 \frac{1}{2}$ per cent spotbill. The only difference between this bird and a pure mallard was said to be the rather more defined and pintaillike vermiculations on the flank feathers. Although this certainly looks like a very remarkable case of segregration, it must be noticed that both the Australian and the spotbill blood, representing $62 \frac{1}{2}$ per cent, are of more or less neutral effect; 
that is, they are both dark, plain-colored species with no secondary sex characters.

Goodale's work on duck hybrids need not concern us, as it dealt with domestic varieties. However, Goodale found that in castrating domestic ducks with mallard plumage the males retained their full plumage, but lost the power of assuming the summer or 'eclipse' plumage (19). The castrated female gradually assumes a more or less complete male dress. He suggested that the female duck owed her plain color to some modifying element which prevents development of male color, and also that this modifier may be sometimes responsible for sex limited inheritance.

$A s$ is well known, cases of females assuming male plumage are very common in domestic ducks, in pheasants, and in other game birds. Apparently it is always due to sterility or disease of ovaries. The converse, however, is very rare. Geoffrey Smith and Mrs. Haig-Thomas (28) reach the conclusion that assumption of hen's plumage by the cock is rare and happens independent of disease or degeneration of the testes, being more in the nature of a transfer of sex characters.

In my own aviaries I once had a pure golden pheasant which had a very remarkable plumage. This bird was given to me, and lived only a short time, so that I do not know its pedigree. In appearance it seemed to have a very much exaggerated youthful male plumage, and looked entirely different from any stage of normal male or female plumage. It showed no evidence of hybridism. On dissection no trace of any sex organs could be detected in this bird, although unfortunately the abdomen was not in good condition at the time of post mortem.

\section{GENERAL DISCUSSION}

In studying birds we are dealing with characters often of quite fundamental systematic importance. Color and pattern in birds, at least in wild species, are known to be a satisfactory basis for classification. In mammals color is notoriously unreliable. The present study has been almost wholly an investigation into the inheritance of male secondary sex-characters. 
In domestic birds the studies of Davenport and others have demonstrated a number of clearly Mendelizing characters. Sex-linked characters have also been described in canaries, pigeons, and fowls.

In our study of wild forms we have found, however, a very different state of things. We have seen that characters often apparently clear-cut and antagonistic do not segregate clearly. For instance, in the cross of golden with Amherst pheasants (not fully described here) the $\mathrm{F}_{1}$ has a mantle color practically pure Amherst although the pattern is intermediate. In $\mathbf{F}_{2}$ and in back crosses to both parents, this mantle color shows every possible gradation from the Amherst pure white, to the almost pure orange-red of the golden pheasant. There are no classes as might be expected from the dominance in $F_{1}$. Again, in the $\mathrm{F}_{1}$ 's the reticulated tail pattern of the golden pheasant is nearly dominant, but there follows very little segregation, and even in back crosses to Amherst this pattern of the golden persists in a tenacious manner up to crosses containing only onesixteenth or one-thirty-secondth of gold blood, as Ghigi has shown.

There is some evidence that in closely related geographical races there is a nearer approach to orthodox Mendelism, but this is never reached, even in back crosses, except occasionally in isolated characters or in the more undifferentiated plumages of the female sex. In species with unrelated character complexes there are only slight tendencies to a greater variation in $F_{2}$ than in $F_{1}$, as is shown in the pintail $\times$ mallard cross, or the Australian $\times$ mallard cross. Such variation, comparable to that seen in size characters, may be explained as the manifestation of factor complexes, outwardly expressed in plumage characters, but not by any means necessarily specific units for these epidermal structures alone.

We have found in the above crosses only two clear-cut characters, that of the 'freak' mallard and that of the 'East India' duck. Neither of these segregating units is in any sense a species character, but closely resembles a large class of variations in domestic mammals and birds. 
It is almost certain that the ordinary sub-species of the ornithologist is very far from being a unit variation.

Sex-linked inheritance is probably a feature of domestic races in birds. In wild species thus far examined there is no slear evidence of unequal transmission by the sexes. Both sexes can carry the characters of the opposite sex through several generations without an additional 'dose' of the character in question. The case of the unequal $F_{2}$ generations in the reciprocal gold $\times$ Amherst cross is as yet unexplained and needs to be further verified. The difference in the sterile reciprocal Reeves $\times$ ringneck cross (25) can probably be explained on other grounds than unequal sex transmission of parental plumages.

A study of species hybrids in birds will satisfy any one that in almost every feather region the minutest details of feather pattern and color show the influence of both parental races. Only in sterile hybrids, or hybrids between distantly related forms, do we find hybrids that are at all puzzling in appearance, as Ghigi has so often pointed out. In such hybrids we must often look for similarities in the youthful, female, or primitive plumages.

In crossing two species, only one of which is sex dimorphic, a more primitive type of male plumage is seen in the hybrids and in the back crosses.

In the mallard, a condition closely resembling eclipse or summer plumage is brought out by crosses with the black duck.

Far larger numbers than have yet been attained would be of great interest in selected species crosses in birds.

I wish to thank Prof. W. E. Casile for his kind assistance in preparing this paper.

\section{LITERATURE CITED}

(1) Bigelow, H. B. 1907 On hybrids between mallards and certain other ducks. Auk, vol. 24, p. 382.

(2) Bonнote, J. L. 1905 On the hybridizing of ducks. Proc. 4th Ornith. Cong., London, p. 235.

(3) 1909 A note on duck hybrids. P. Z. S., p. 598.

(4) Buturlin, Sergivs A. 1908 The true pheasants. The Ibis, pp. 570-592.

(5) Cronan, C. 1902 Der Jagfasan. Paul Parey, Berlin, p. 12. 
(6) Dewar and Finn. 1909 The making of species. John Lane, London, p. 97.

(7) FINN, F. 1913 Some spontaneous variations in mallard and Muscovy ducks. Avicultural Mag., 3rd series, vol. 4, no. 3, p. 82.

(8) Ghigi, Armssandro 1903 Contribuzione alla biologica e systematica dei Phaseanidae. Archivio Zool. Ital., vol. 1, pp. 289-338.

(9) 1907 Contributi allo studio dell' ibridismo negli uccelli. Rend. R. Accad. de Lincei., vol. 16, pp. 791-800.

(10) 1908 Sulla dissociazione dei caratteri specifici negli ibridi complessi di alcune uccelli. Rend. R. Acad. Lincei., vol. 17, pp. 452-461.

(11) 1908 Sopra un caso di mutazione nel G. Swinhoii. R. Accad. delle Scienze dell' Instituto di Bologna, marzo, pp. 1-14.

(12) 1907-08 Sviluppo e comparsa di caratteri sessuali secondari in alcuni uccelli. Rend. R. Accad. delle Scienze Bologna.

Ital. di Omithologia, vol. 2, pp. 65-85.

(19) Goodale, H. D. 1910 Some results of castration in ducks. Biol. Bull., vol. 20, no. 1, pp. 35-62.

(20) Haig-Thomas, R. 1909 On some skins of hybrid pheasants. Proc. Zool. Soc., p. 884 .

(21) 1912 Experimental pheasant breeding. Proc. Zool. Soc., pp. 538-546.

(22) 1914 The transmission of secondary sexual characters in pheasants. Jour. Genetics, vol. 3, no. 4.

(23) Phillips, J. C. 1912 a A reconsideration of the American black ducks, etc. Auk., vol. 29 , pp. 295-306.

(24) 1912 b Size inheritance in ducks. Jour. Ex. Zoöl., vol. 12, p. 369.

(25) 1913 Reciprocal crosses between the Reeves and common pheasant, etc. Am. Naturalist, p. 701.

(26) 1914 A further study of inheritance of size in ducks. Jour. Ex. Zoöl., vol. 16, p. 131.

(27) Rogmron, G. Les canards. J. B. Balliere et Fils, Paris, p. 135.

(28) Sмiтн, G., and Haig-Thomas, R. 1913 On sterile and hybrid pheasants. Jour. Genetics, vol. 3, p. 39.

(29) Townsend, C. W. 1912 Auk, p. 176.

(30) Wright 1886 Book of poultry, p. 540. 


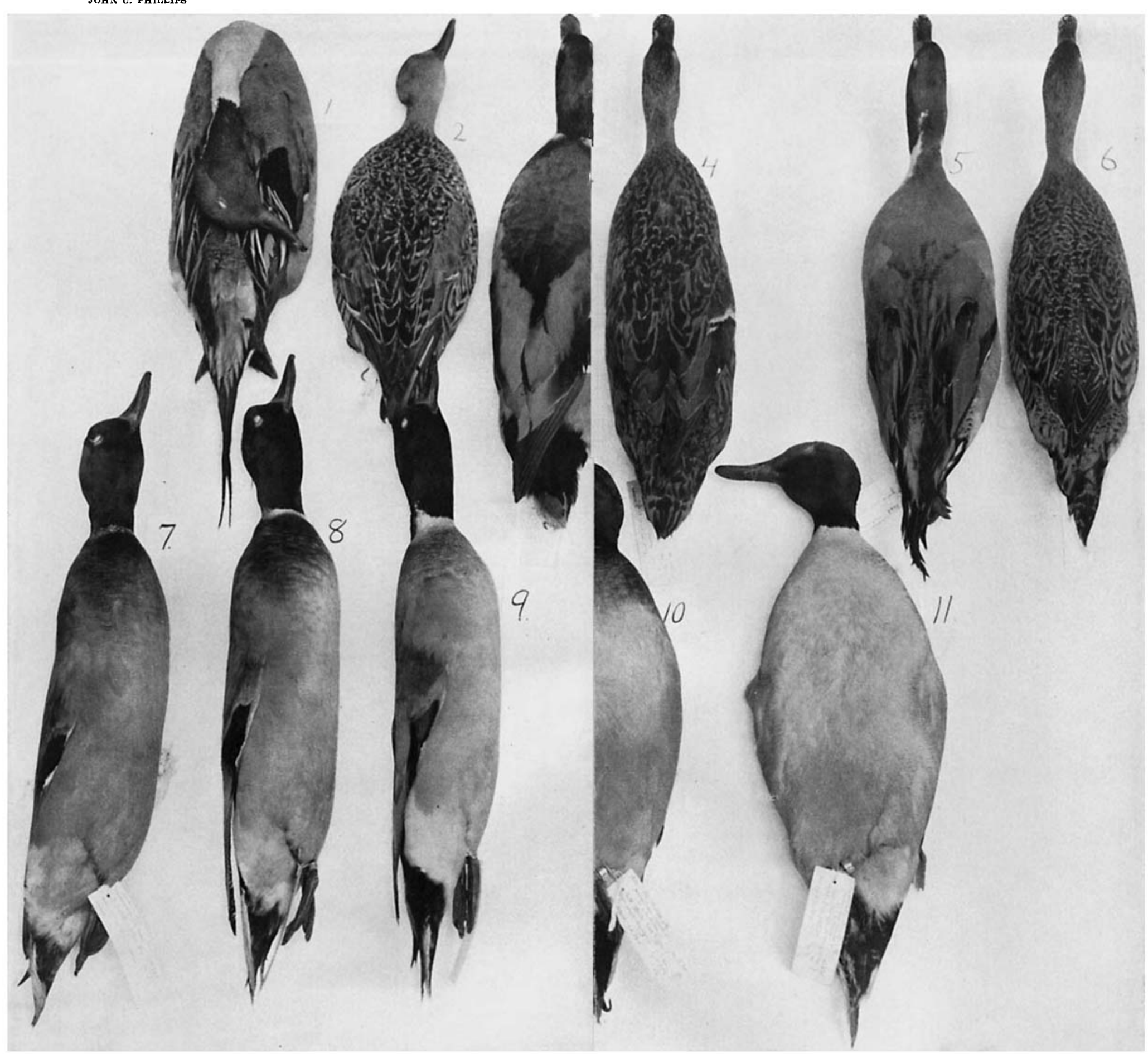

Pintail $\times$ mallard experiment.
1 Pintail duck of.
2 Pintail duck 0
3 Mallard on. 4 Mallard 9

$5 \quad \sigma\left[\left(F_{1}\right.\right.$ pintail $\times$ mallard $) \times$ pintail $\mid$ showing mallard characters in lessen

black scapular patch, shorter central tail feathers, shorter neck, ete. $\quad F_{2}$ gencration $\sigma^{\prime}$, showing most marked pintail variation, No. 525. The
6 o $\left[\left(F_{1}\right.\right.$ jintail $\times$ mallard $) \times$ pintail $]$ shows a bird very close to pure pintarence in the color of the heads between figures 10 and 11 does not show in the $Q$, but having some mallard characters.
Lo $9 \quad F_{1}$ hybrids from of pintail and o mallard. ligure 8 represents type $F_{1}$ males, No. 966; figure 7 is extreme variation in the direction of mallard 53; figure 9 is extreme variation towards pintail duck No. 84!.

$\mathrm{F}_{2}$ generation $\sigma^{\prime}$, showing most marked pintail variation, No. 525. The ograph. 


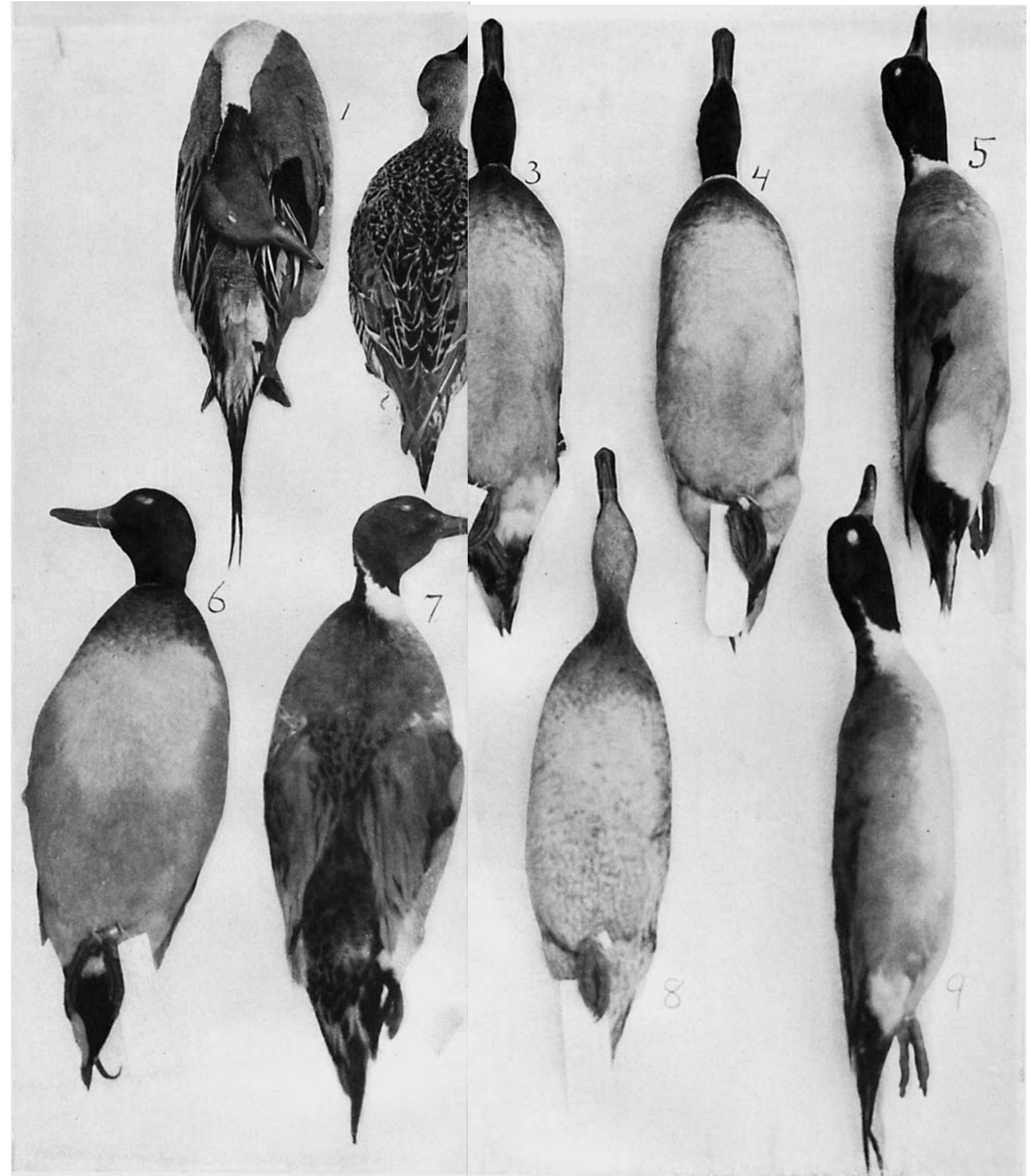

Pintail $\times$ mallard experiment.

1 to 7 Same specimens as in plate 1 , but mallards left out

1 Pintail duck $0^{7}$. 2 Pintail duck $q$.

$6 \mathrm{~F}_{2}$ व $\mathrm{No} .530$

3 to $5 F_{1} \sigma^{x} \sigma^{x}$ showing full extent of variation in $F_{1}$

$7 \mathrm{~F}_{2} \sigma^{7}$ No. 525 (dorsal view).

8 o [ $\mathrm{F}_{1}$ pintail $\times$ mallard $) \times$ pintail] ventral view.

a $[(F$, pintail $\times$ mallard $) \times$ pintail $]$ side view. 


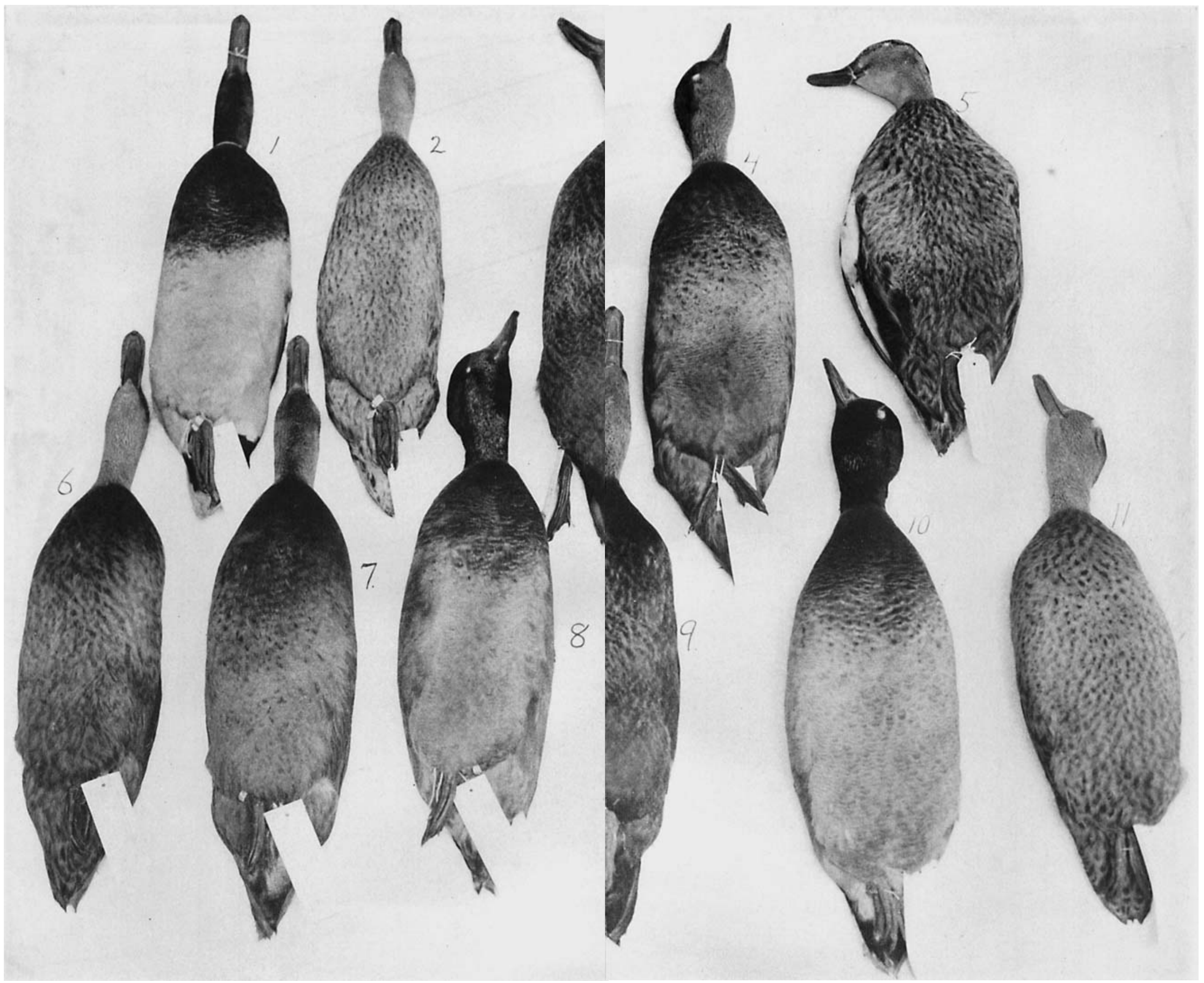

Mallard $\times$ black duck experiment.

8 or No. 174, marked variate in direction of mallard, having nearly solid 1 Mallard $\sigma^{7}$. 2 Mallard o. 3 Black duck (a. tristis) male or fecen head and a chestnut breast, but the latter poorly marked off posteriorly, etc. $4 F_{1} \sigma^{7}$ from cross or black $\times \odot$ mallard (call) $5 F_{1}$ ofrom cross $o^{7}$ black $\times \circ$ mallard (call). d by pattern on breast feathers (pl. 9, fig. 9).

o From $F_{1} 8 \times \sigma^{7}$ black duck-very close to black duck, but always to be

6 to 8 or $\sigma^{7} \mathrm{~F}_{2}$ types. $6 \sigma^{7}$ No. 61, type of $\mathrm{F}_{2}$ generation. $7 \sigma^{\pi}$ No. 3710 or From $F_{1} q \times$ mallard $\sigma^{7}$, same as $F_{1} \sigma^{7} \times$ mallard $q$. ate towards mallard, showing blackish chin, dark breast, black under tail coverts 11 q From $\mathrm{F}_{1} \% \times$ mallard $\sigma^{7}$, same as $\mathrm{F}_{1} \sigma^{7} \times$ mallard $q$. 


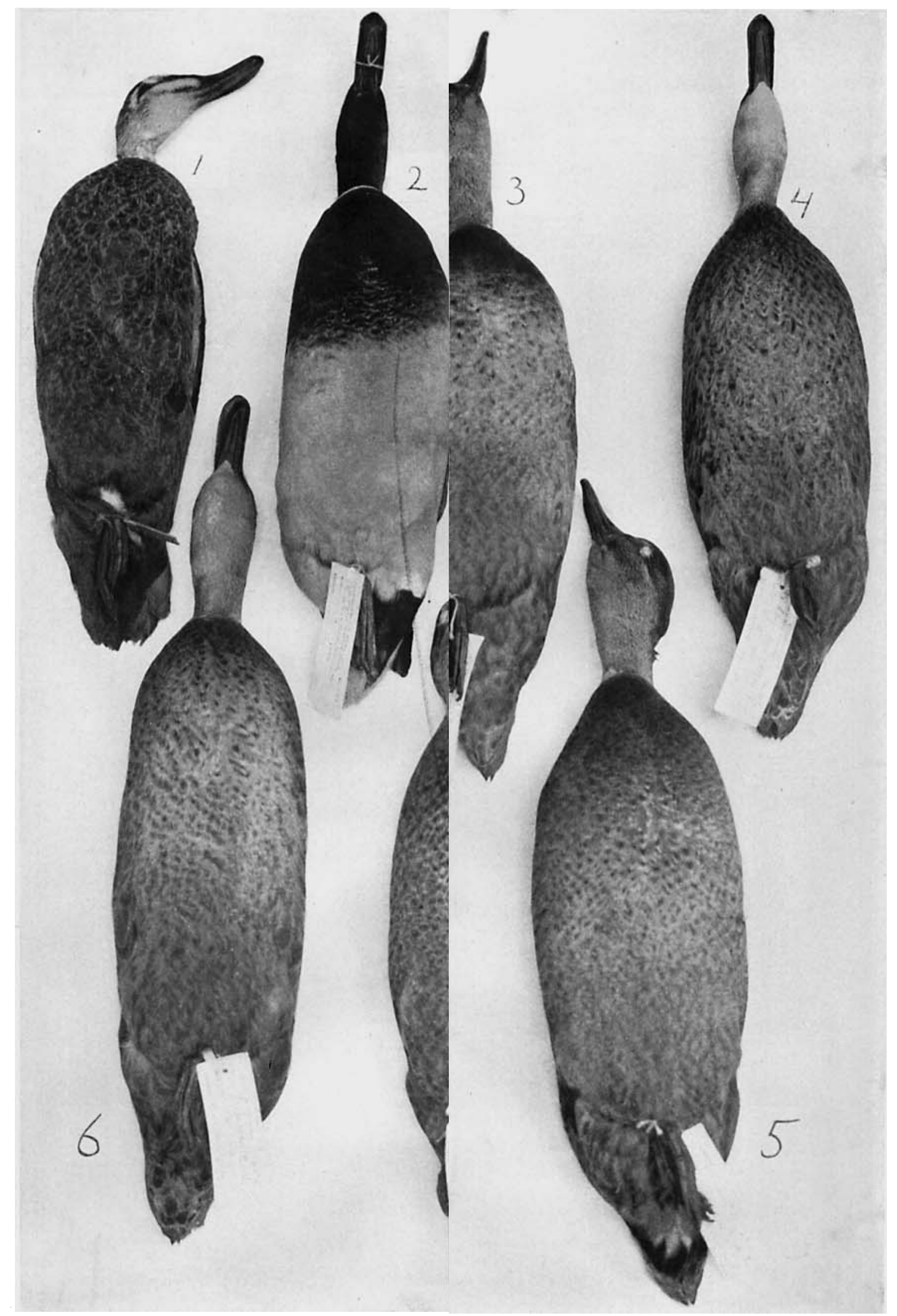




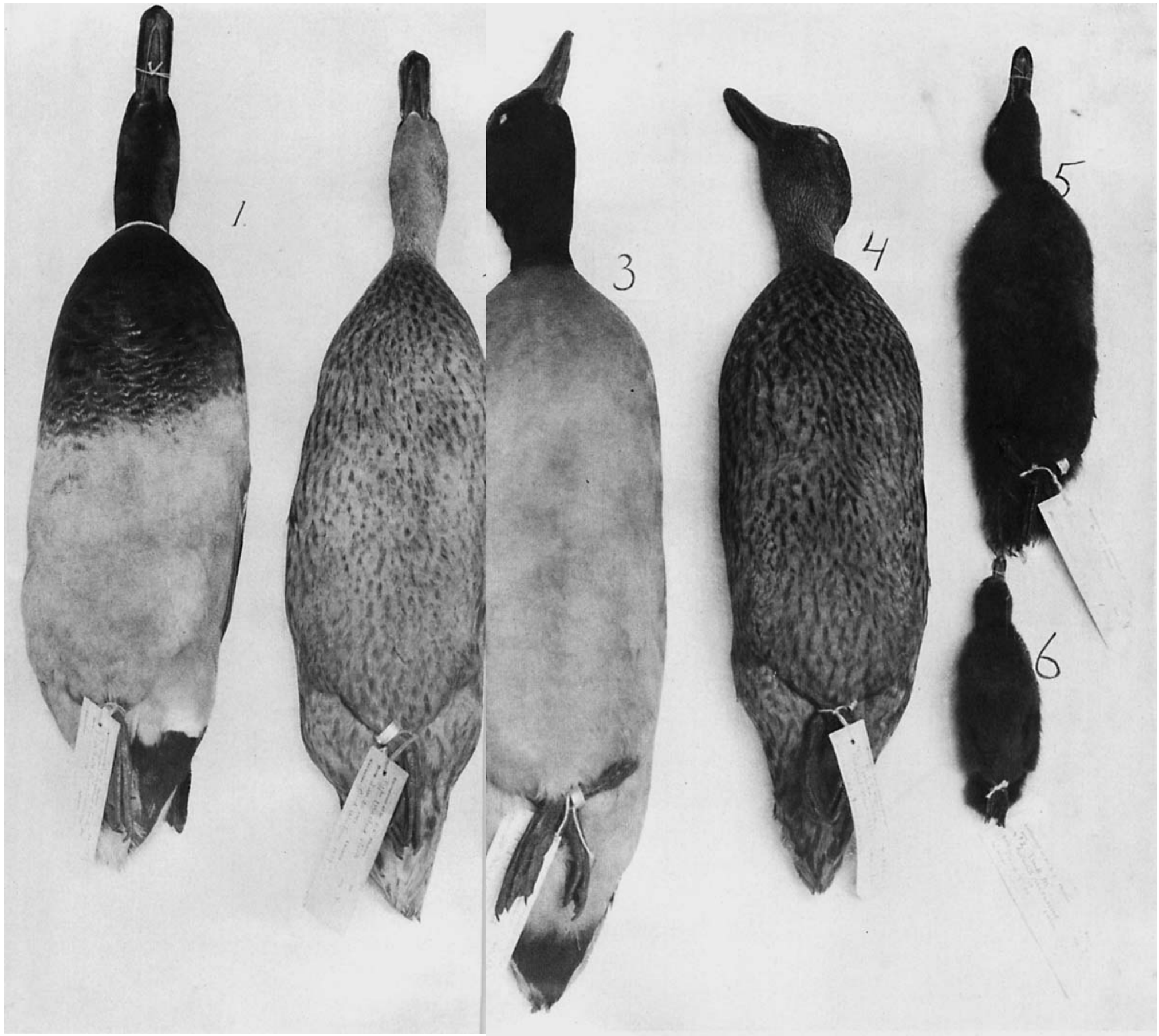

Freak mallard experiment.

1 Mallard $\sigma^{7}$. 2 Mallard o.

3 Original male freak, or No. 39-256
4 Extracted $\mathrm{F}_{2} \&$ freak No. 219. The darkness of this bird is slightly exaggerated in the plate.

5 to 6 Young extracted freaks in down plumage, either sex. 


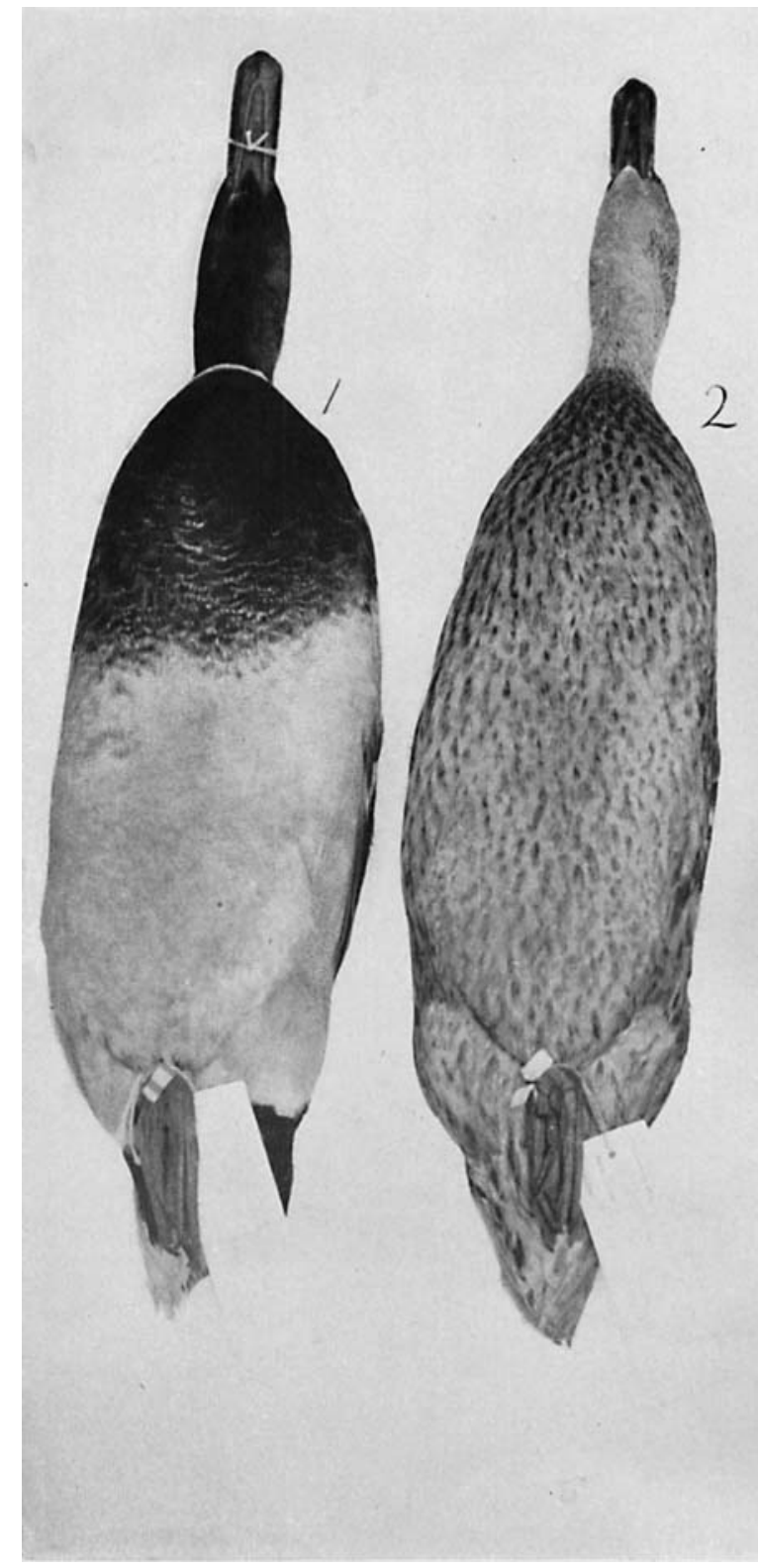

Mallard $\times$ East Indian experiment

3 Extracted $\mathrm{F}_{2}$ mallard male dark type (contaminated). 134

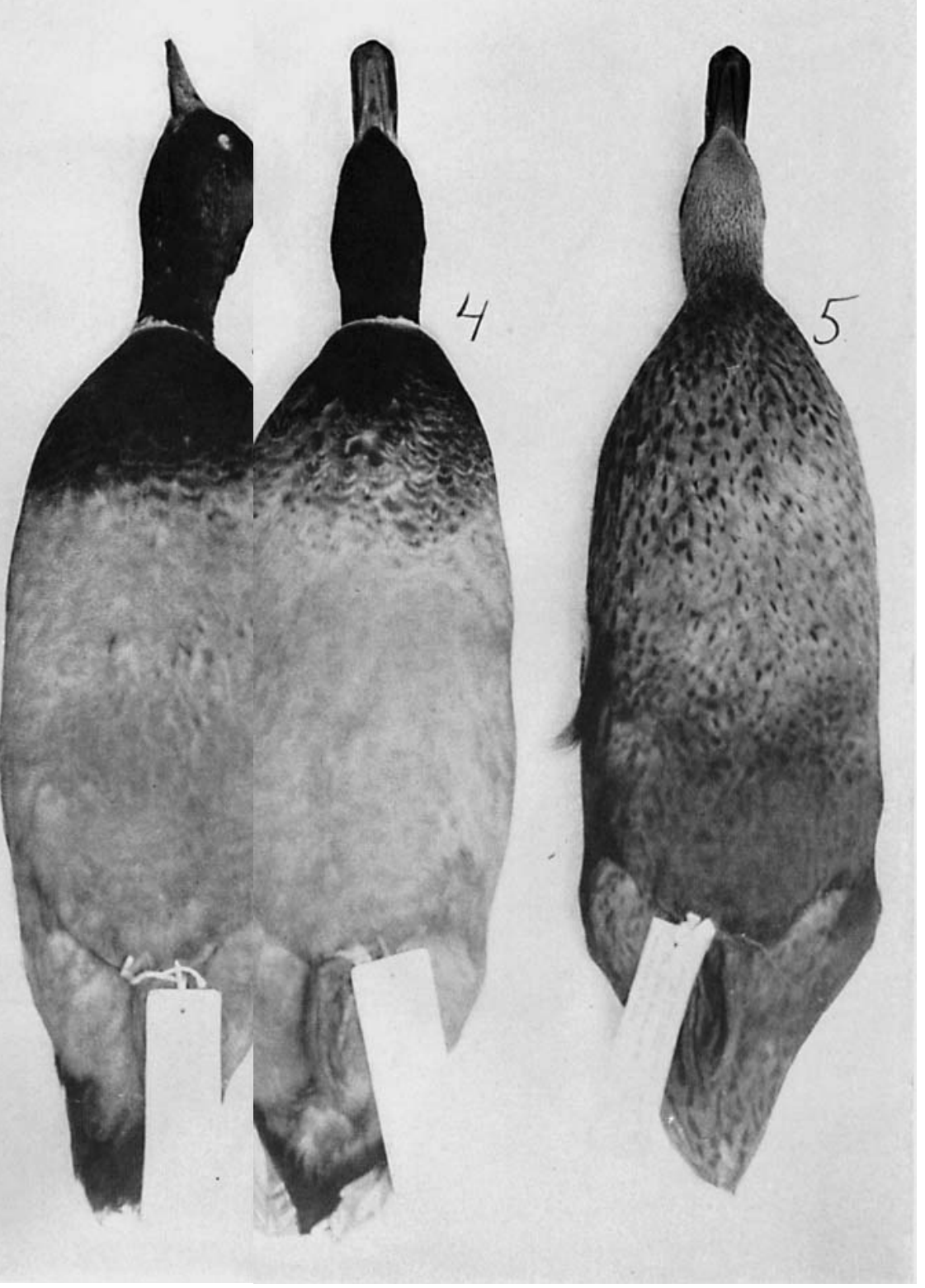

racted $\mathrm{F}_{2}$ mallard male practically pure mallard. racted $\mathrm{F}_{2} \subsetneq$ mallard, showing a bird darker all over than pure mallard, he lower abdomen sooty; all females are like this. 


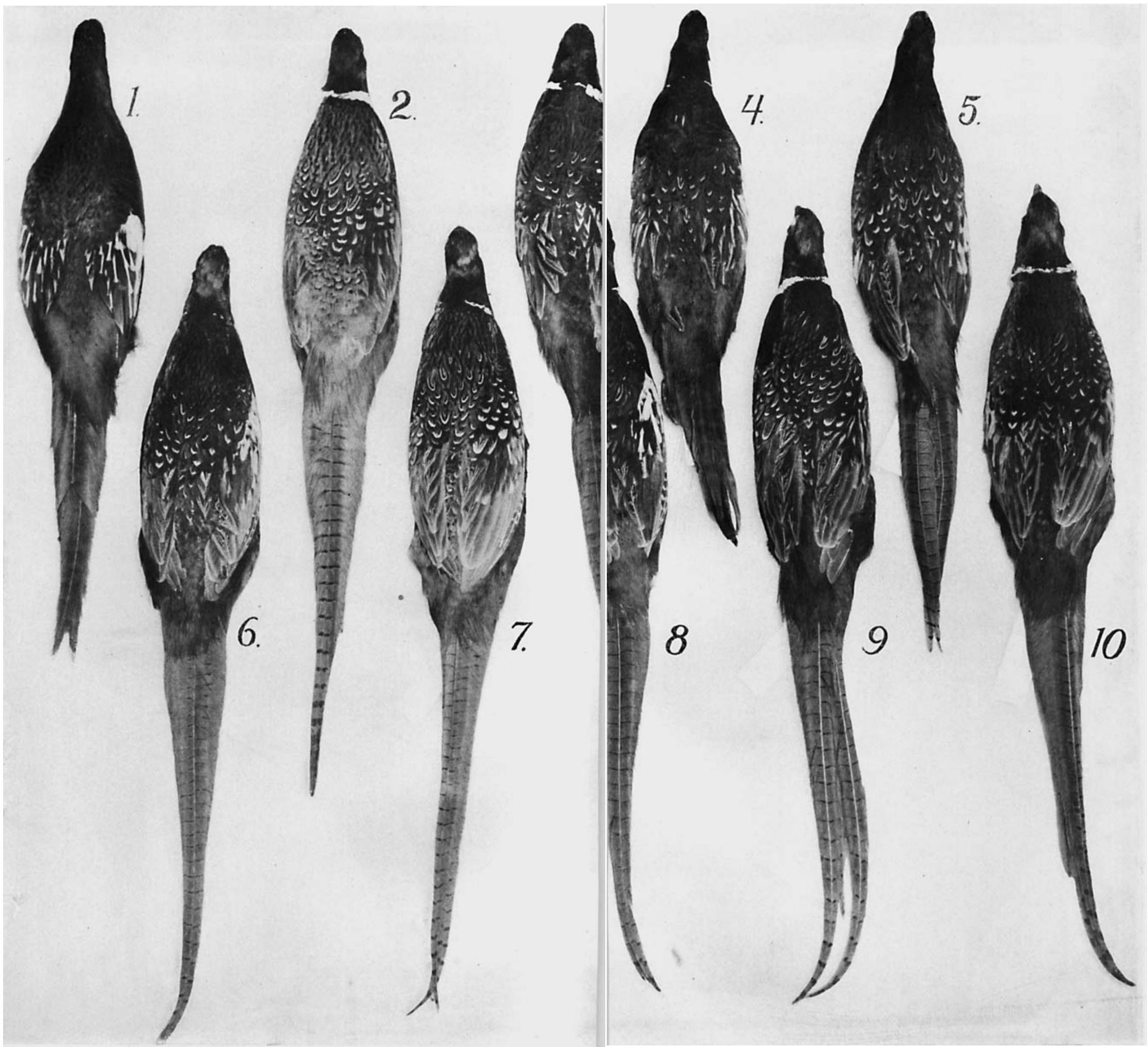

Prince of Wales $\times$ ring neck experiment.

1 Prince of Wales, P. principalis $0^{7}$

2 Ring neck $P$. torquatus, $\sigma^{T}$ (type of ring neck stock)

$3 \mathrm{~F}_{1} \mathrm{O}^{\pi}$ (intermediate tail bars, rump color, neck-ring and wing coverts).
, $\sigma^{7} \sigma^{7}$ Produced by crossing $q F_{1}$ back to $P$. principalis $o^{\pi}$. Figure losest approach to pure principalis; No. 831 .

$0 \quad F_{2} \sigma^{x} \sigma^{7}$ arranged from small neck ring on left to large neck ring on ter characters do not show well in plate. 


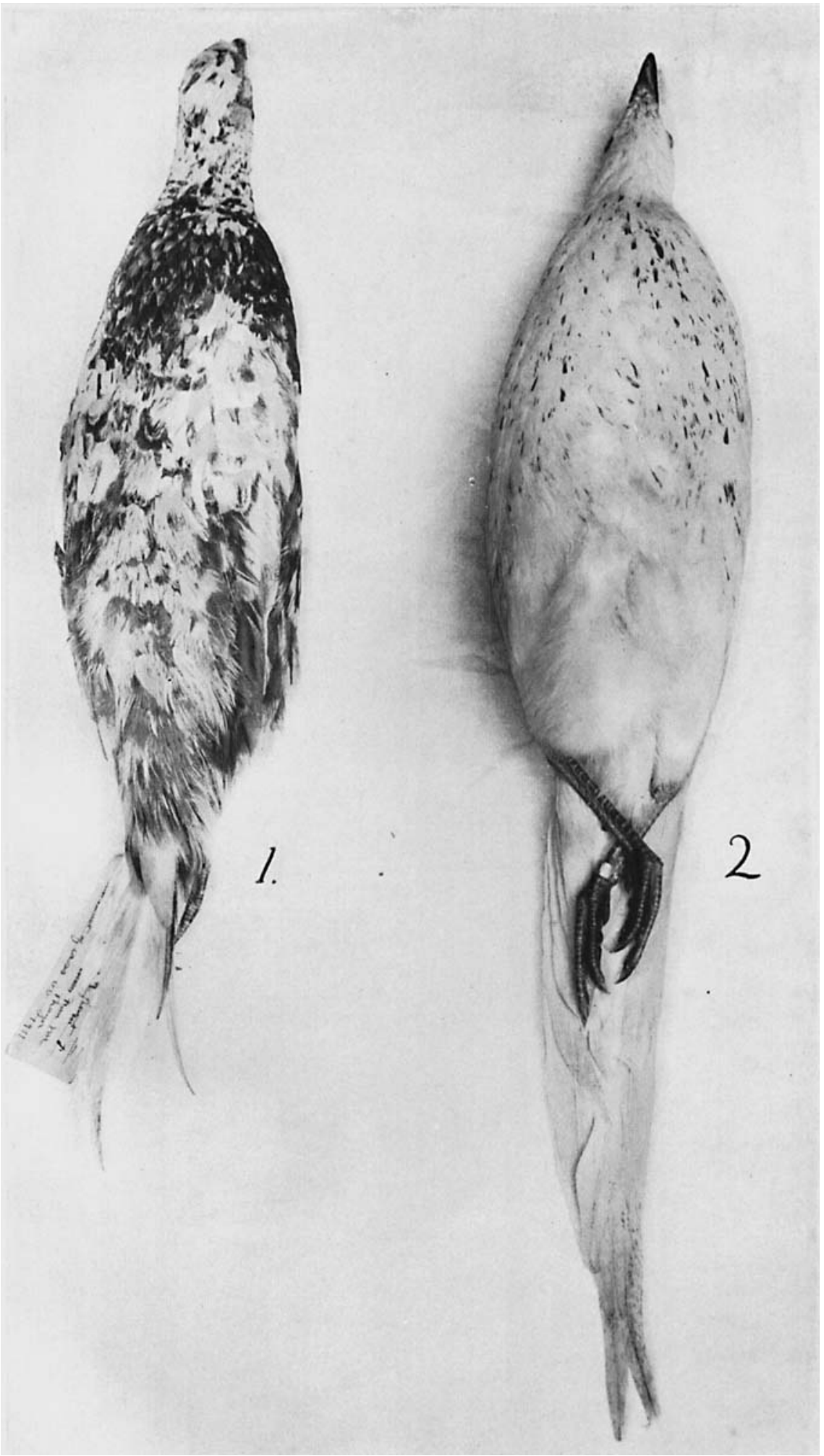

\section{Albino pheasant experiment}

1 Original spotted ring-neck (torquatus) male dorsal view.

2 A typical $F_{3}$ generation or from selected $F_{2}$ parents; ventral view; some of this series are whiter than this specimen. 
PISATE O

FX PI.ANATION OF FICI'KES

Brenst feathers of male ducks

1 Pure blnek duek A. tristis (the fine hrownish line probubly shows mallard affinities).

2 Pure Australian A. superciliosa.

3 Pure inallard, chestnut area, full plumage.

+ Pure mallard, chestmut area, eclipse plumagc.

5) Hybrid produced by hack orossing $F_{1}$ (mallard $X$ black) with pure mallard; breatst, feathers of a type intermediate between full mallard plumage :ncl celipse mallarit plumage.

$6 \cdot F_{1}$ or $F_{2}$. Black $\times$ mallard, showing primitive eclipse mallard feather puttern.

$7 \quad F_{1}$ or $F_{2}$. Australian $\times$ mallard, showing primitive eclipuse mallard feather pat.tern.

$8 \mathbf{F}_{1}$ or $\mathrm{F}_{2}$. Pintuil $X$ mallaril; shows mallard chestnut, but poorly aleveloped and with no primitive mallard pattern.

9 Threc-fourths blood black duck, $F_{1}$ (mallarl $\times$ black) $\times$ black.

10 Three-fourths blood Australian duck, $F_{1}$ (mallard $\times$ Australinu) $\times$ Australian. Both figures 9 and 10 preserve the primitive mallard pattern seen in $\mathrm{F}_{\mathrm{l}}$ and $\mathrm{F}_{2}$.

11 Three-fourths blood pintail duck $F_{1}$ (mallard $\times$ pintail) $\times$ pintail; a faint crearny stain is all that is left of the mallard chestnut. 
JOHN C. PHILLIPE
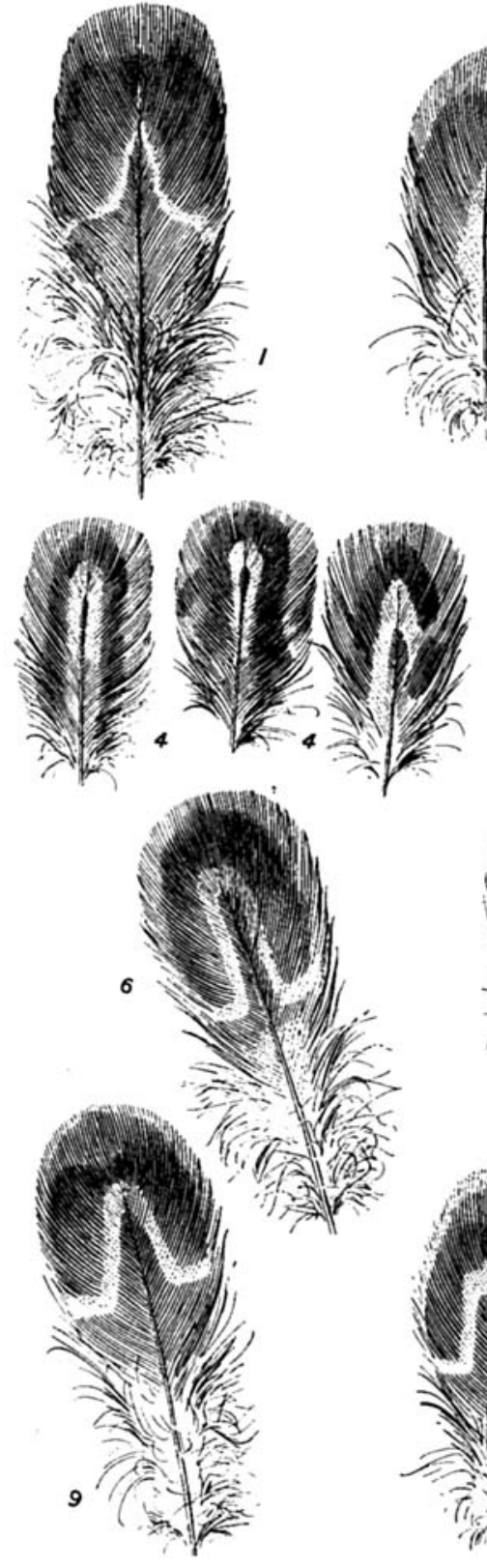
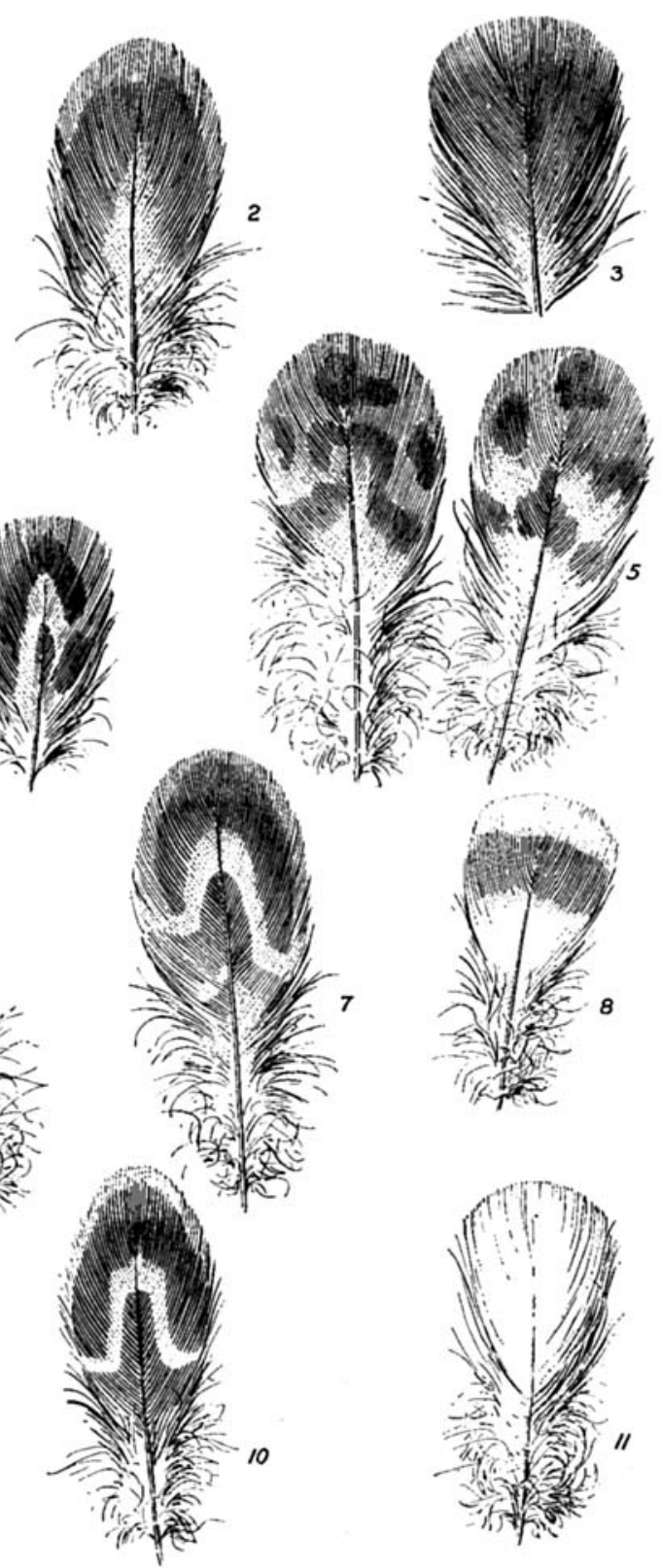